\title{
SiDNA and Other Tools for the Indirect Induction of DNA Damage Responses
}

\author{
Maria Quanz ${ }^{1,2}$, Amélie Croset ${ }^{1,2}$ and Marie Dutreix ${ }^{1}$ \\ ${ }^{1}$ Institut Curie, Centre National de Recherche Scientifique (CNRS) UMR3347, \\ Institut National de la Santé et de Recherche Médicale (INSERM) U1021, \\ Université Paris-Sud 11, Centre Universitaire, 91405 Orsay \\ 2DNA Therapeutics SA, 91058 Evry \\ France
}

\section{Introduction}

Cells respond to DNA damage by activating an intricate signaling network leading to DNA repair, cell cycle arrest or apoptosis. In recent years, progress has been made in the discovery and characterization of a number of DNA repair pathways, and it has become apparent that the inhibition of specific components of these pathways could offer new targets for combating the resistance of tumors to chemotherapy or radiotherapy. A thorough understanding of the various DNA repair pathways and their regulation is therefore essential. The DNA damage response (DDR) is of great importance in determining cell fate decisions. It includes many signal amplification steps and several steps that are partly redundant due to the ability of different kinases to phosphorylate the same target. Furthermore, the timing and origin of the damage play an important role in determining the DNA repair pathway activated. All this makes it difficult to study the role of one particular protein in DNA damage signaling. In addition, the available tools for activating DNA repair pathways are mostly agents that systematically produce more than one type of DNA damage. Even if the damage caused is initially of one predominant type (as for topoisomerase inhibitors, alkylators or the I-SceI endonuclease system), the damage may rapidly be transformed by normal cellular processes, such as DNA replication, or specific nuclease activities. Studies of the DDR become even more complicated if the agent used to create DNA lesions also damages other cellular components, as is the case for ionizing radiation (IR), alkylators and hydrogen peroxide. Furthermore, the damage is transient, as DNA damage signaling is rapid and lesions are quickly repaired. The signal induced by the damage therefore disappears rapidly, soon after the induction of damage. In some cells, the DNA may not be successfully repaired, leading to apoptosis or senescence. These aspects make it difficult to study the signaling network induced by a given type of damage.

In this chapter, we will provide an overview of the response of the cell to DNA damage and possible ways of inducing a DDR in cells without actually damaging chromatin. We will focus on stabilized short interfering DNA molecules (siDNA), which mimic different types of damage and induce a pure damage-specific response. 


\section{DNA-damaging treatments induce multiple and dynamic responses}

DNA is a stable material, as required for the storage of genetic information, but it is also susceptible to spontaneous changes under normal cellular conditions. It has been estimated that each cell spontaneously loses about 5000 purine bases (depurination) every day (Friedberg, 1995). The deamination of cytosine to uracil also occurs spontaneously. In addition to this inherent instability, our genomes are exposed to numerous endogenous or environmental agents, including reactive metabolites, environmental chemicals and ultraviolet radiation, capable of inducing a wide diversity of DNA lesions (Figure 1). The large number of different lesions possible - more than 100 different oxidative modifications

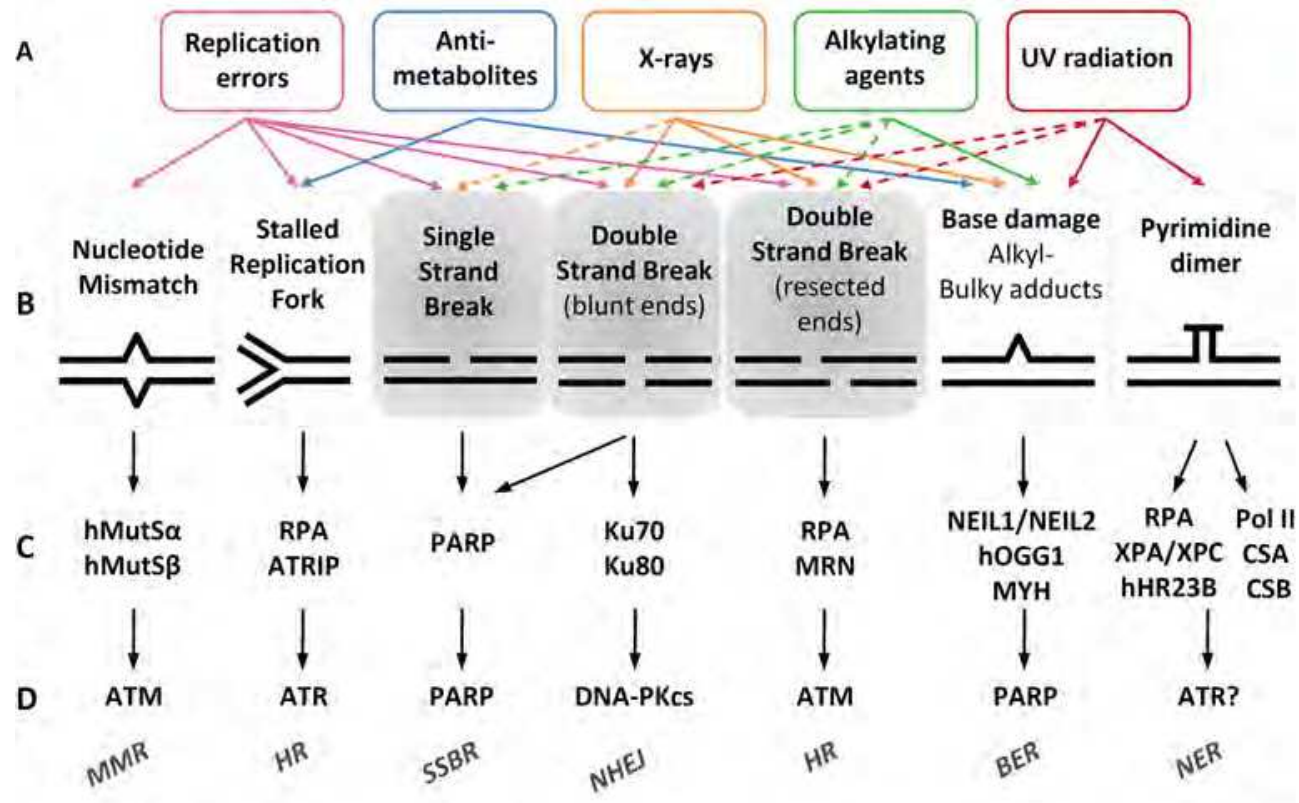

Fig. 1. DNA-damaging treatments induce multiple and dynamic responses mediated by DNA damage sensors and transducers. Common DNA-damaging agents (A) induce several types of DNA damage (B) directly (solid line) or indirectly (dotted line). Single- and double-strand breaks (highlighted in gray) are the most frequent end products of unrepaired damage. DNA damage is recognized by sensor proteins (C) that recruit and/or activate transducers (D), initiating a signal transduction cascade (not shown). Abbreviations: ATM, ataxia telangiectasia mutated; ATR, ataxia and rad3-related; ATRIP, ATR-interacting protein; BER, base excision repair; CSA or CSB, Cockayne Syndrome A or B; DNA-PKcs, DNA-dependent protein kinase catalytic subunit; hOGG1, human 8-hydroxyguanine DNA-glycosylase; HR, homologous recombination repair; hHR23B, human Rad23 homolog B; MMR, mismatch repair; MRN, Mre11-RAD50-Nbs1; MYH, MutY glycosylase homologue; NEIL1, nei endonuclease VIII-like 1; NER, nucleotide excision repair; NHEJ, non-homologous end joining; PARP, poly(ADP-ribose) polymerase; RPA, replication protein A; SSBR, single-strand break repair; UV, ultraviolet; XPC, xeroderma pigmentosum group C. 
alone have been identified in DNA (Cadet et al., 1997) - has led to the evolution of many different repair pathways for sensing and repairing the various types of damage.

The complete signaling network for each damage type and its individual contribution to the cellular damage response are not fully understood, but the essential repair mechanisms have been elucidated (reviewed for example by Fortini \& Dogliotti (2007); Friedberg (1995; 2001); Helleday et al. (2008); Li (2008); Wyman \& Kanaar (2006)). Figure 1 summarizes the main pathways and highlights the sensors (DNA binding proteins that recognize specific DNA lesions) and transducers (enzymes that amplify the damage signal by posttranslational modification of downstream targets) involved in repair and signaling for particular types of damage. The main DNA damage transducers are the phosphoinositide 3-kinase-like kinase (PIKK) family members ATM (ataxia telangiectasia mutated), ATR (ataxia telangiectasia and Rad3-related) and DNA-PK (DNA-dependent protein kinase). A DNA break signal can also be transduced by poly(ADP-ribose) polymerases 1 or 2 (here both designated PARP), which use $\mathrm{NAD}^{+}$to catalyze the modification of their targets with negatively charged, long and branched ADP-ribose polymers. We provide below a brief description of the DNA repair pathways, the subsets of damage they repair and the transducers that are activated.

\subsection{Repair processes that do not directly activate transducers}

The direct repair of certain alkylation adducts and other uncomplicated base modifications by specialized single enzymes is probably the simplest repair mechanism. O6-alkylguanine DNA alkyltransferase (AGT) is a major enzyme involved in direct repair. It is encoded by the O6-methylguanine-DNA-methyltransferase (MGMT) gene and transfers the alkyl adducts produced by alkylating agents, such as temozolomide, dacarbazine or nitrosourea compounds, from O6-methylguanine, O4-methylthymine, O6-ethylguanine or O6-chloroethylguanine to a cysteine residue within the active site of the enzyme, thereby inactivating the enzyme (Gerson, 2004). Other direct repair enzymes include the DNA dioxygenases $\mathrm{ABH} 2$ and $\mathrm{ABH}$, which can convert 1-methyladenine and 3-methylcytosine back into adenine and cytosine, respectively (Duncan et al., 2002). The repair of alkylated lesions is a rapid process, with most alkylated sites successfully repaired within an hour (Zhu et al., 2009). The types of damage targeted by direct repair processes do not seem to be associated with the activation of damage signaling kinases, probably due to the rapid repair kinetics and the absence of intermediate strand break generation during the repair process.

\subsection{Repair mechanisms that activate mainly PARP as a transducer}

The base excision repair (BER) pathway recognizes and removes bases carrying non-bulky modifications that have been damaged by nonenzymatic alkylation, oxidation, ring saturation, or IR (Chan et al., 2006). BER also eliminates deaminated bases and DNA single-strand breaks (SSBs). As a first step in BER, a damage-specific DNA glycosylase (e.g. hOOG1, NEIL1 or NEIL2) recognizes and excises the damaged base, leading to the formation of a potentially cytotoxic intermediate apurinic or apyrimidinic site (AP site) (Bandaru et al., 2002; Boiteux \& Radicella, 2000). The abasic sugar is cleaved by an AP endonuclease (APE1), which generates a strand break that is further processed by PARP, DNA polymerase $\beta$ and ligase III in either short-patch or long-patch pathways (Fortini \& Dogliotti, 2007). PARP not only recognizes the intermediate SSB but also acts as a damage transducer amplifying the damage signal by linking poly(ADP-ribose) (PAR) chains to its substrates, including itself. These polymers bind specific proteins, including XRCC1, DNA ligase III, p53 and DNA-PK, 
affecting the repair process as well as downstream responses to DNA damage (Malanga \& Althaus, 2005).

\subsection{Repair pathways that lead to PIKK activation}

Most repair pathways involve the activation of PIKKs as transducers, especially if DNA breaks persist. Since PARPs can also sense DNA breaks, an implication of these enzymes in the pathways described in the following cannot be excluded.

\subsubsection{Nucleotide excision repair}

The nucleotide excision repair (NER) pathway senses and repairs various bulky, helix-distorting lesions that block DNA replication and transcription (Hanawalt, 2002). These lesions may arise, for example, following exposure to genotoxic compounds, such as polycyclic aromatic hydrocarbons or cisplatin. Two major repair mechanisms are known to be involved in this pathway: transcription-coupled repair, which specifically targets lesions blocking RNA polymerase II, and global genome repair, which deals with lesions in the rest of the genome (Cleaver, 2005). The damage sensors involved in transcription-coupled repair include, in addition to RNA polymerase II, Cockayne Syndrome A and B proteins. By contrast, XPA, Rpa and the XPC-hHR23B complex recognize lesions during global genome NER (Brown et al., 2010; Reardon \& Sancar, 2005). NER is a complex multistep process involving the recognition of disrupted base pairing followed by unwinding of the DNA helix around the lesion and dual incision. The oligonucleotide patch carrying the lesion is excised, and the remaining gap is filled by regular DNA replication, using the intact complementary strand as a template. The main transducer kinase activated by the NER pathway is probably ATR, in response to UV-induced DNA damage in particular (Shell et al., 2009).

\subsubsection{Mismatch repair}

Mismatch repair (MMR) targets mispaired bases and nucleotides and insertion-deletion loops that arise through errors in DNA replication. The mechanisms by which eukaryotic cells distinguish mismatched from correctly matched bases in non replicating DNA remain unclear, but it is thought that recognition involves the contact of MMR proteins with the replication machinery. The eukaryotic mismatch sensors are the heterodimeric hMutS $\alpha$ (MSH2-MSH6) and hMutS $\beta$ (MSH2-MSH3) complexes. Whereas hMutS $\alpha$ preferentially recognizes base-base mismatches and insertion/deletion mispairs of one or two nucleotides, hMut $\beta$ recognizes larger insertion/deletion mispairs ( $\mathrm{Li}, 2008)$. The removal of mismatched bases and the restoration of strand integrity resemble the processes occurring in BER and NER. MMR proteins can interact with proteins in other repair pathways, such as BER, NER and homologous recombination, suggesting coordinated crosstalk between these processes (Kunkel \& Erie, 2005). hMutS $\alpha$ and hMutS $\beta$ may directly activate DNA damage signaling by physical interaction with ATM, ATR-ATRIP, c-Abl, and the p53-related transcription factor p73 (Kim et al., 2007; Shimodaira et al., 2003; Yoshioka et al., 2006). Consistently, hMutS $\alpha$ and hMutS $\beta$-deficient cells are defective in cell cycle arrest in response to multiple types of DNA damaging agents $(\mathrm{Li}, 2008)$. Another model proposes that a DDR could be activated by DNA breaks that are produced during "futile" DNA repair cycles. This model suggests that strand-specific MMR, which targets only newly replicated DNA, engages in repetitive repair cycles when it encounters a DNA lesion in the template strand, and this futile cycling activates ATR and/or ATM signaling leading to cell cycle arrest and apoptosis (Li, 1999; 2008). 


\subsubsection{Double-strand break repair pathways}

It is generally accepted that the DNA double-strand break (DSB) is one of the most toxic and mutagenic DNA lesions occurring in human cells. A single DSB can, if left unrepaired, lead to the loss of a chromosome fragment and, thus, the death of the cell. However, despite the potential danger posed by DSBs, eukaryotic cells have evolved ways of improving biological processes based on the controlled induction of a DSB. Examples of this include the generation of variation during meiosis (Inagaki et al., 2010) and in the immune system (Fugmann et al., 2000), and the relaxation of supercoiled DNA by topoisomerases. Another endogenous source of DSBs are reactive oxygen species (ROS) produced by normal cellular processes, such as oxidative respiration, cytochrome P450 metabolism, peroxisomes and inflammatory responses. Examples of exogenous sources of DSBs will be described below.

DSB repair occurs via two main pathways: non homologous end-joining (NHEJ) and homologous recombination (HR) repair (Wyman \& Kanaar, 2006). In mammalian cells, NHEJ is the major pathway for repairing breaks not associated with replication. This process may occur in all phases of the cell cycle, but predominantly in G1 phase. NHEJ involves the direct rejoining of two damaged DNA ends in a sequence-independent manner (Helleday et al., 2007; Weterings \& van Gent, 2004). This end-joining mechanism is very precise for blunt ends and other simple end structures (van Heemst et al., 2004). However, the processing of incompatible ends may result in sequence alterations, such as deletions, occurring at "complicated" breaks. DNA double-strand breaks are first sensed by the ring-shaped $\mathrm{Ku} 70 / 80$ heterodimer. This DNA-Ku70/80 complex then attracts and activates the serine/threonine kinase activity of the DNA-PK catalytic subunit (DNA-PKcs). Following correct end alignment, DNA-PKcs is autophosphorylated (Weterings \& Chen, 2007) and makes the ends available for ligation by ligase IV/XRCC4. Another essential NHEJ factor involved in the ligation of DSBs is XLF/Cernunnos (Ahnesorg et al., 2006; Buck et al., 2006). The MRN (Mre11 (Meiotic recombination 11)-Rad50-Nbs1 (Nijmegen breakage syndrome 1)) complex may facilitate the alignment of the two DNA ends, particularly when end processing is required (de Jager et al., 2001; Moreno-Herrero et al., 2005). The processing of "complex" lesions, such as hairpins, damaged backbone sugar residues, damaged bases, aberrant $5^{\prime}$ hydroxyl groups or 3' phosphate groups, may involve polynucleotide kinase (Chappell et al., 2002; Koch et al., 2004), the RecQ helicase WRN (Perry et al., 2006), DNA polymerases $\mu$ and $\lambda$ (Nick McElhinny et al., 2005) and the structure-specific nuclease Artemis (Ma et al., 2002; Moshous et al., 2001).

It has recently been suggested that there is an alternative or "backup"-NHEJ (B-NHEJ) pathway that functions in conditions in which the NHEJ pathway is compromised (Iliakis, 2009). The B-NHEJ pathway seems to be dependent principally on histone H1 (Rosidi et al., 2008), PARP, which binds to DSBs with an even greater affinity than that with which it binds SSBs (D'Silva et al., 1999), and DNA ligase III/ XRCC1 (Audebert et al., 2004).

Whereas NHEJ repairs DNA in a template-independent fashion by rejoining two broken ends, HR can accurately resynthesize damaged or missing sequence information at the break site, using homologous sequences as a template, preferably the adjacent sister chromatid in S or G2 phase. Several mechanisms of HR have been identified (reviewed for example by Helleday et al. (2007) and Hartlerode \& Scully (2009)). All are initiated by $5^{\prime} \rightarrow 3^{\prime}$ resection at the DSB end, facilitated by the MRN complex (Paull \& Gellert, 1998), which plays a critical role in the sensing of DSBs for HR. The MRN complex also recruits and helps to activate ATM (Lee \& Paull, 2004; 2005). In addition to MRN, other factors, including CtIP (CTBP-interacting 
protein), Exo1 and BLM (Bloom's syndrome protein), are required for 5'-end resection in mammalian cells (Hartlerode \& Scully, 2009; Sartori et al., 2007; Yun \& Hiom, 2009). After resection, single-stranded DNA (ssDNA) rapidly binds the ssDNA-binding protein RPA, which is then replaced by multimers of the Rad51 recombinase, forming a nucleoprotein filament at the end of the ssDNA. Rad51 loading involves direct interaction with BRCA2 (Pellegrini et al., 2002) and other factors (Hartlerode \& Scully, 2009; Sy et al., 2009). The Rad51 nucleoprotein filament then captures double-stranded DNA (dsDNA) and scans it for homology (Bianco et al., 1998). When a homologous region is encountered, the 3 '-end of the invading strand is extended by a polymerase, using the duplex DNA as a template. From this stage on, the repair pathway may diverge. The DSBR (DNA double-strand break repair pathway, also known as the double Holliday junction model) pathway mostly results in chromosomal crossover, whereas the SDSA (synthesis-dependent strand annealing) pathway ends with non crossover products (Johnson \& Jasin, 2000; Liu \& West, 2004; Van Dyck et al., 2001).

\subsection{Dynamics and heterogeneity of DNA damage}

One challenge in the study of the cellular response to DNA damage is the multitude of lesions introduced by most genotoxic agents. For instance, the exposure of cells to IR results in damage to all components of the cell, including lipids, proteins and nucleic acids. IR acts directly on the DNA, causing breaks in its phosphodiester backbone. This process accounts for about 30\% of the DNA damage induced by IR (Chapman et al., 1973). The radicals produced by the indirect effects of radiation may account for as much as $70 \%$ of the DNA damage induced by IR (Chapman et al., 1973). These radicals damage DNA, resulting in a wide diversity of DNA lesions, such as damage to bases and the backbone sugar (oxidation, rearrangement, adducts), intrastrand crosslinks, the formation of abasic sites, single- and double-strand breaks and DNA-protein crosslinks (Jeggo \& Lavin, 2009). Complex lesions, such as clustered DSBs and LMDS (locally multiply damaged sites) may also occur. After these complex lesions, DSBs are the most harmful lesions to the cell (Ward, 1975). It has been shown, in rodent cells, that the extent of cell death is directly correlated with the yield of DSB under various X-ray irradiation conditions (Radford, 1985). IR is therefore often used in investigations of the cellular response to DSBs. However, DSBs are not the most frequent type of lesion induced by IR. A dose of 1 Gy, for example, induces about 1000 SSBs and 150 protein-DNA crosslinks, but only 40 DSBs (Friedberg, 1995).

The reaction of various alkylating agents with DNA leads to the formation of highly heterogeneous products. Some agents may preferentially produce certain alkylation products, but the DNA damage generated is never limited to a single type (De Bont \& van Larebeke, 2004). Furthermore, as for IR, other cell components, including proteins and ribonucleic acids, may be modified. Cellular responses to these modifications, such as activation of the proteasomal degradation pathway, may interfere with DDR pathways, or be involved in crosstalk with these pathways.

One type of damage can be transformed into another by inefficient repair and DNA replication or transcription (Figure 2). As described above, DNA repair pathways, such as BER, MMR and NER, generate intermediate SSBs. These SSBs may result in DSBs, if the repair is incomplete and the lesion persists (Bonner et al., 2008). The transformation of SSBs into DSBs occurs, for example, when replication forks encounter a SSB on the template and collapse (Strumberg et al., 2000) (Figure 2). Common types of DNA damage interfering with replication fork 


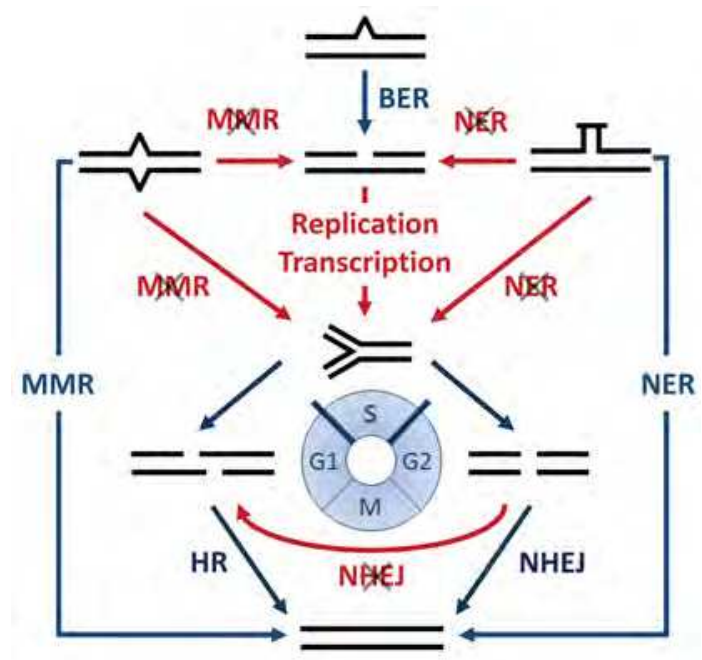

Fig. 2. Transformation of DNA damage. DNA lesions are normally repaired by the corresponding repair pathways. However, deficient repair may result in SSBs or DSBs. If a lesion persists during S-Phase (blue circle), stalled replication forks may arise. The collapse of a stalled replication fork results frequently in DSBs. DNA damage symbols and abbreviations are as for Figure 1.

progression are adducts of DNA bases (Helleday et al., 2008). By the same mechanism, inhibitors of DNA synthesis may also indirectly cause DSBs, as they impair replication fork progression (Lundin et al., 2002). Such inhibitors include aphidicolin, which inhibits DNA polymerases (Ikegami et al., 1978) and hydroxyurea, an inhibitor of ribonucleotide reductase (Bianchi et al., 1986). Topoisomerase inhibitors induce DSBs by exploiting the natural activity of topoisomerases during DNA replication. Topoisomerases resolve the DNA torsions induced during replication, by introducing a transient break in the DNA. Inhibitors of topoisomerases prevent the resealing of the break, by trapping the enzyme in a complex with the DNA (Hsiang et al., 1989; Kohn et al., 1987).

Thus, DSBs are the final outcome of unrepaired damage at the end of all these transformation processes (Figure 2). It is therefore not surprising that redundant and well regulated mechanisms have evolved for detecting, in particular, the presence of this toxic lesion and for activating DDR. DSBs can activate DNA-PK directly and they also activate ATM and ATR after end resection (Lopez-Contreras \& Fernandez-Capetillo, 2010; Smith et al., 2010). Under certain conditions, PARP may also signal the presence of a DSB (Iliakis, 2009). The direct precursors of DSBs - SSBs and stalled replication forks - may themselves induce DDR, but there is less redundancy in the detection of these structures. SSBs are probably recognized and signaled to damage checkpoints mostly by PARP (Bouchard et al., 2003) and aberrant replication forks induce ATR activity through the recognition of RPA-coated stretches of ssDNA (Lopez-Contreras \& Fernandez-Capetillo, 2010). The lack of redundancy in the signaling of these structures may account for their frequent transformation into DSBs. 


\subsection{Cellular DNA damage response}

DNA breaks, including DSBs in particular, induce a highly coordinated DDR process leading to signal amplification, enhanced repair functions, cell cycle arrest or apoptosis. Many proteins are implicated in the DDR, which involves complex spatial and temporal coordination and many dynamic interactions between repair proteins and DNA.

\subsubsection{Spatiotemporal organization of the DNA damage response}

The components of the DDR pathway may be classified roughly as DNA-damage sensors, mediators, transducers and effectors (Figure 3A). After the sensing of a DNA break, mediator and repair proteins rapidly accumulate on the chromatin surrounding the lesion, to form subnuclear repair foci (Fernandez-Capetillo et al., 2003) (Figure 3B). Protein recruitment to DSBs normally occurs in a hierarchical manner and involves multiple posttranslational modifications, such as phosphorylation, ubiquitination, PARylation or acetylation (Essers et al., 2002; Lukas et al., 2004; Polo \& Jackson, 2011). The massive accumulation of DNA repair and signaling factors may lead to structural stabilization of the break. The amplification and maintenance of the DNA-damage signal through the recruitment of multiple copies of transducer kinases to sites of damage is probably an even more important function (Misteli \& Soutoglou, 2009).
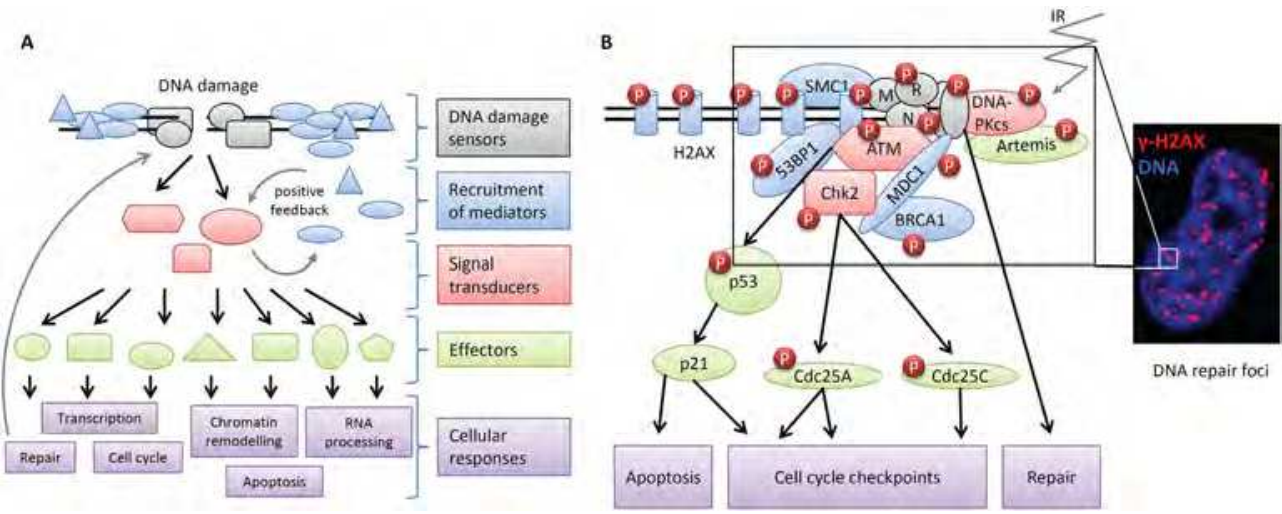

Fig. 3. The DDR signal transduction cascade. (A) DNA damage is first physically recognized by sensor proteins (gray). Mediator proteins (blue) facilitate the recruitment and activation of transducer kinases (red). A positive feedback loop between mediators and transducers leads to the maintenance and amplification of the signal. The transducer kinases then phosphorylate various effector proteins (green), including kinases, transcription factors and repair proteins. Depending on the severity of the damage, this can lead to various cellular responses (purple). (B) Formation of multiprotein complexes at the sites of DSBs (Ward \& Chen, 2004) and microscopic visualization of the formation of $\gamma-\mathrm{H} 2 \mathrm{AX}$ foci in response to IR. The exposure of cells to IR results in the rapid recruitment of numerous proteins to the sites of DNA lesions. The signal transducing kinases ATM and the related DNA-PK initiate a cascade of phosphorylation events (P), amplifying the signal to activate, if necessary, cell cycle checkpoint pathways or apoptosis, in situations in which the damage is too great to be repaired. 
DNA break sensors include the MRN complex (Rupnik et al., 2008), Ku70/80, PARP and RPA. Break recognition by these sensors leads to the activation of transducer kinases, such as the PIKKs ATM, ATR and DNA-PK as well as PARP (Iliakis, 2009; Stiff et al., 2004; Ward \& Chen, 2001). ATM, DNA-PK and ATR can phosphorylate the serine 139 residue of the histone variant $\mathrm{H} 2 \mathrm{AX}$ (yielding $\gamma-\mathrm{H} 2 \mathrm{AX}$ ), at nucleosomes around the lesion. H2AX phosphorylation is probably the earliest posttranslational modification in DDR and may be considered the initial signal amplification step. $\gamma-\mathrm{H} 2 \mathrm{AX}$ formation is followed by binding of the mediator protein MDC1 (mediator of DNA damage checkpoint 1) to the DSB-flanking chromatin (Jungmichel \& Stucki, 2010). Mediator or adaptor proteins help to transmit, enhance and sustain the signaling between sensors and transducers, leading to the spread of the repair machinery along the chromosome. Other mediators include 53BP1 (p53-binding protein 1) and BRCA1 (Li \& Zou, 2005; Misteli \& Soutoglou, 2009). The recruitment of 53BP1 and BRCA1 to the DSB is indirect, requiring the activity of the E3 ubiquitin ligases RNF8 (Huen et al., 2007; Kolas et al., 2007) and RNF168 (Doil et al., 2009; Stewart et al., 2009). ssDNA compartments may be bound by RPA, which subsequently recruits ATR (Lobrich \& Jeggo, 2007) and Rad51. Foci of Rad51 binding colocalize with Rad52 (Liu \& Maizels, 2000), Rad54 (Essers et al., 2002), RPA (Raderschall et al., 1999), BRCA1 (Scully et al., 1997) and BRCA2 (Chen et al., 1998). Sustained activation of the transducers results in the transmission of the damage signal to effectors, which relay the signal to downstream pathways with endpoints in different cellular processes, such as checkpoint arrest or apoptosis (Kastan \& Bartek, 2004) (Figure 3).

Not all the actors in DNA damage signaling and repair form characteristic foci. Unlike ATM, MDC1, 53BP1, BRCA1/BARD1 and MRN, the central NHEJ proteins Ku70/80 and DNA-PK do not spread to the adjacent chromatin upon recruitment to the break, presumably because they are required at low copy number at sites of damage (Bekker-Jensen et al., 2006; Lukas et al., 2003). The same is true for the effector kinases Chk1 and Chk2, and for p53, which interact only transiently with damage sites, subsequently diffusing rapidly to relay the signal to their soluble downstream targets.

One endpoint of the described signaling cascade in response to DNA damage is the activation of checkpoints to provide the cell with more time for DNA repair. DDR checkpoints have been identified at the G1/S and G2/M boundaries, and during S phase and, potentially, in mitosis (reviewed by Lukas et al. (2004)). After activation, the transducer kinases ATM, ATR or DNA-PK phosphorylate p53 either directly or via ATM-induced activation of the effector kinase Chk (checkpoint kinase) 2. Phosphorylated p53 then induces transcription of the gene encoding the Cdk inhibitor p21, which ultimately prevents transition from G1 to S-phase. Both Chk 1 and 2 activate the G2/M and intra-S checkpoints (Smith et al., 2010). It was long thought that ATM principally phosphorylated Chk1 and that ATR preferentially phosphorylated Chk2. However, this view has been modified by the discovery of various crosstalk between these kinases (Bartek \& Lukas, 2003). The precise role of DNA-PK in this regulation remains unclear. PARP may contribute to checkpoint signaling by activation of p53. p53 exhibits high affinity for automodified PARP (Malanga et al., 1998) and p53 functions are impaired in PARP-deficient cells (Wang et al., 1998; Wieler et al., 2003). Furthermore, PARP activation in response to excessive DNA damage leads to extensive $\mathrm{NAD}^{+}$consumption. The cellular $\mathrm{NAD}^{+}$depletion can induce cell death through several mechanisms, depending on the cellular context (reviewed by Rouleau et al. (2010)). 


\subsubsection{Complexity of DNA damage response regulation}

The outcomes of DNA damage signaling are, literally, a matter of life or death. Depending on the severity of DNA damage, the cell will either repair the damage to enable it to continue dividing or enter apoptosis. Complex, redundant signaling pathways converging on several central node proteins have emerged to ensure that this signaling remains under tight control. These node proteins must obtain input signals from several sources, in the form of protein modifications, before they can relay the signal to downstream effectors. This has a protective effect, greatly reducing the risk of important cell fate decisions, such as entry into apoptosis, occurring in response to a single erroneous input signal (Yarosh, 2001). The nodes in DDR include checkpoint proteins, such as Chk1 and Chk2, which control cell cycling and require input signals from several sources for full activation (McAdams \& Arkin, 1999). Another prominent example for a node protein in DNA damage signaling is p53 (Kohn, 1999). The p53 protein has 11 sites for phosphorylation and acetylation, and can theoretically assume about 2000 modification states, if all the possible independent combinations are taken into account. Twelve different kinases can phosphorylate p53, and activated p53 can interact with at least 15 downstream proteins (Yarosh, 2001). The kinases that phosphorylate p53 in response to DNA damage include DNA-PK, ATM and ATR. Full p53 activity requires phosphorylation by both DNA-PK and ATM, at least (Wang et al., 2000). It is therefore now thought that p53 plays a key role in determining the degree of damage, through the assessment of input signals, on which the decision as to whether apoptosis is necessary is based (Kohn, 1999). There is a need to determine the specific conditions under which individual PIKKs become activated. Which (genotoxic) stresses lead to the activation of all transducer kinases? Is it possible to activate a single PIKK specifically, without affecting the others, and what are the cellular consequences of this?

There is also direct interplay between the transducer kinases (Chen et al., 2007). PIKKs can phosphorylate each other in response to DNA damage, resulting in mutual control of their activities. In addition to mediating posttranslational modifications, the kinases seem to regulate each other, either directly or indirectly (Peng et al., 2005). Studies on mutants and siRNA experiments have shown that a decrease in the amount of one of these kinases often leads to a decrease in the amounts of the PIKK sister kinases. The location of the kinases also seems to play an important role. For ATM, for example, the concentration of multiple copies in repair foci plays an important role in kinase activation, whereas DNA-PK does not need such an accumulation of multiple copies for full activation.

Another layer of complexity is added by the partially overlapping substrate specificities of the transducers ATM, DNA-PK and ATR (reviewed by Durocher \& Jackson (2001) and Yang et al. (2003)). These transducers signal different types of DNA damage, but it was recently shown that the PIKK-mediated signaling network is highly extensive, with hundreds of phosphorylation events at ATR, ATM and DNA-PK consensus target sites induced by IR (Matsuoka et al., 2007). As discussed above, the plethora of types of damage induced by IR results in the activation of all three PIKKs. It remains to be determined which substrates are specific or overlapping for which transducer kinases in this long list of potential PIKK targets. Further insight into the contributions of individual repair signaling pathways has been provided by studies of the responses induced by damage signals in the absence of chromatin damage. This aspect will be discussed below. 


\section{Methods and mechanisms for inducing a damage response in the absence of chromatin damage}

The induction of DNA damage repair pathways by exogenous DNA was first reported in bacteria, into which UV-irradiated lambda bacteriophages (D'Ari \& Huisman, 1982; George et al., 1974) or plasmids (Bailone et al., 1984) were introduced. This indirect response is controlled by activation at the sites of exogenous DNA damage of the RecA protein, the key enzyme of the bacterial damage signaling response known as the "SOS response" (see Schlacher \& Goodman (2007)). No such mechanism was initially found in mammals, despite a few publications reporting that UV-irradiated H-1 parvovirus or SV40 simian virus induced an "SOS-like" repair pathway in infected mammalian cells (Cornelis et al., 1982). Elucidation of the mechanisms underlying the response to damaged DNA or RNA in the cell took much longer in mammals. We review here the mammalian cell response to oligonucleotides, viral and immunostimulatory DNA and the insight into DDR gained from the analysis of artificial repair foci.

\subsection{Cellular response to DNA oligonucleotides}

In bacteria, ssDNA has been identified as the signal triggering the bacterial SOS repair response. The RecA protein (Rad51 in humans) is directly stimulated by ssDNA, inactivating the LexA repressor and triggering the repair response (Craig \& Roberts, 1981). It has been suggested that ssDNA (at SSBs, stalled replication forks or resected DSBs) acts also as the major stimulatory signal for DNA damage responses in eukaryotic cells (Li \& Deshaies, 1993; Nur et al., 2003). Several studies based on transfection or the microinjection of synthetic DNA oligonucleotides have analyzed the response of the cell to ssDNA. Studies by Nur et al. (2003) have shown that ssDNA acts upstream from ATM/p53 in DNA damage signaling. The transfection of cells with short (as few as 5 bases) ssDNA molecules with random sequences induced ATM activation and apoptosis, whereas very short ( $8 \mathrm{bp}$ ) dsDNA molecules did not (Nur et al., 2003). The induction of apoptosis by ssDNA is consistent with earlier studies, in which transfection with randomly fragmented DNA (Schiavone et al., 2000) or the nuclear injection of linearized plasmid DNA, circular DNA containing a gap, or single-stranded circular phagemids induced cell cycle arrest or apoptosis (Huang et al., 1996). The activation of ATM by fragmented DNA requires the MRN-assisted assembly of short, linear ssDNA fragments into high-molecular weight complexes, as shown by experiments in Xenopus laevis extracts (Costanzo et al., 2004).

So, if ssDNA can activate ATM directly, how is ATM activated in response to DNA double-strand breaks? When DNA double-strand breaks are sensed by the MRN complex, MRN partially unwinds the ends to expose ssDNA (Lee \& Paull, 2005). It has been shown in Xenopus laevis egg extracts that $70 \mathrm{bp}$ synthetic double-stranded molecules are rapidly resected in an MRN-dependent manner to generate ssDNA oligonucleotides, which activate ATM (Jazayeri et al., 2008). Consistent with these findings, the injection of small synthetic ssDNA oligomers into undamaged cells also induces ATM activation, and the elimination of ssDNA oligomers results in the rapid extinction of ATM activity. In summary, the results obtained from experiments with single-stranded or long double-stranded DNA fragments suggest that short ssDNA molecules are the essential signal for the induction of ATM-dependent cell cycle arrest and apoptosis. 
The cellular response to single-stranded oligonucleotides may also have consequences for targeted gene repair with synthetic oligonucleotides. In gene targeting processes, ssDNA molecules are transported to the nucleus, where they align with their complementary sequence in the target gene, facilitating nucleotide exchange (Brachman \& Kmiec, 2002). However, the introduction of large amounts of oligonucleotides into cells may induce cell cycle arrest and stalled DNA replication in the corrected cells, due to the ATM activation by the mechanism described above. Ferrara \& Kmiec (2006) showed that the transfection of human colorectal cancer cells with 47-mer single-stranded oligonucleotides mostly activated Chk1 and Chk2 in corrected cells. As a consequence, uncorrected cells may outgrow corrected cells. The uncorrected cells probably contain fewer oligonucleotides, too few indeed to generate a local ssDNA concentration high enough to activate ATM. This may account for previous reports of the decline of corrected populations over time (Igoucheva et al., 2004).

\subsection{Synthetic interstrand crosslinks}

The cytotoxic activity of many chemotherapeutic agents, including cisplatin, nitrogen mustards and mitomycin C, is due to the induction of interstrand crosslinks (ICLs) in DNA. These lesions block the strand separation necessary for essential DNA functions, such as transcription and replication. ICLs affect both strands of the chromosome, and their repair is particularly complex. It involves factors from multiple repair pathways and the mechanisms may differ at different stages of the cell cycle. Nucleotide-excision repair, homologous recombination repair, the Fanconi anemia repair pathway, MMR and translesion synthesis have all been shown to participate in ICL repair.

Oligonucleotides containing synthetic ICLs are a valuable tool for the study of ICL repair (Guainazzi \& Scharer, 2010). The advantage of such molecules over cell treatment with a cross-linking agent is that it is possible to study the components involved in the repair of specific interstrand crosslink products one at a time. This has mostly involved the ligation of the synthetic ICL-containing DNA fragments into plasmids, followed by analysis of their repair in cell-free extracts or cells (Orelli et al., 2010; Raschle et al., 2008; Wang et al., 2001). The repair of the specific ICL can be analyzed with reporter genes or by enzymatic digestion followed by Southern blotting. Studies with synthetic DNA ICLs have contributed to our understanding of the mechanism of replication-coupled DNA ICL repair (Wang et al., 2001) and the role of the Fanconi anemia pathway in this repair process (Knipscheer et al., 2009).

\subsection{Viral infection}

The highly organized cellular response to DNA damage may be disorganized or hijacked during viral infection (Lilley et al., 2007; Weitzman et al., 2004). Viruses often produce large amounts of exogenous DNA during infection, and generate proteins that interfere with DNA repair pathways and cell cycle checkpoints. Recent studies have suggested that the cellular DNA repair machinery can recognize viral nucleic acids as damage (Lilley et al., 2007). In some cases, the host DNA repair response is inactivated by viruses, whereas in others, the maintenance of a functional host DNA repair machinery seems to increase viral replication. Studies of the interaction of viruses with the host cell DNA repair machinery have improved our understanding of normal cellular DNA repair functions, and viruses may be useful model systems for studying certain aspects of DNA repair (Weitzman \& Ornelles, 2005). In this section, we provide an overview of the ways in which viral infection can activate the DDR in cells, thereby focusing on the response to viral genomic material. For a detailed description 
of the ways in which viral proteins can manipulate the host DNA repair machinery and cell cycle checkpoints, we refer the reader to Chaurushiya \& Weitzman (2009), Davy \& Doorbar (2007) and Weitzman et al. (2004).

\subsubsection{DDR induction by DNA viruses}

Adenoviruses (Ad), which belong to the parvovirus family, are probably the most thoroughly investigated DNA viruses. Their genome consists of a linear, $36 \mathrm{~kb}$ dsDNA molecule, with inverted terminal repeats (ITRs) at each end and origins for DNA replication (Weitzman \& Ornelles, 2005). Viral proteins synthesized before viral DNA replication prevent the recognition of the Ad genome by host DNA repair factors. This may involve the targeting, by these proteins, of cellular damage sensors and repair effectors, such as the MRN complex or DNA ligase IV, for degradation and relocalization (Carson et al., 2003; Stracker et al., 2002). Infection with Ad lacking the proteins required for blockade of the host DNA repair machinery results in partial DDR activation. DNA damage mediator proteins accumulate at sites of viral replication (Stracker et al., 2002) and $\gamma-\mathrm{H} 2 \mathrm{AX}$ is formed at the periphery of viral centers, in a process dependent on host cell PIKK activity (Carson et al., 2003). Despite the interference of viral proteins with the cellular DNA repair system during infection with wild-type Ad, the cellular DDR does not seem to be completely abolished. The foreign DNA induces H2AX phosphorylation during later stages of infection, after the onset of viral DNA replication (Nichols et al., 2009). H2AX phosphorylation follows a pan-nuclear pattern, suggesting that all the $\mathrm{H} 2 \mathrm{AX}$ on the host chromatin is phosphorylated by ectopic kinase activation, contrasting with the localized $\gamma-\mathrm{H} 2 \mathrm{AX}$ formation observed in response to DSBs in the chromatin. Viral replication seems to be required for this phosphorylation, because infection with a nonreplicating virus does not induce $\gamma$-H2AX (Nichols et al., 2009) production. ATR may be the principal kinase phosphorylating H2AX in these conditions, although ATM and DNA-PK also seem to be involved (Nichols et al., 2009).

Pan-nuclear H2AX phosphorylation has also been observed in cells infected with the adeno-associated virus (AAV) (Collaco et al., 2009; Fragkos et al., 2008; Schwartz et al., 2009). The AAV genome, like that of Ad, consists of an ssDNA molecule with ITRs at both ends, resulting in the formation of double-hairpin structures (Brown, 2010). AAV infection requires helper functions, which may be supplied by Ad or other viruses (Geoffroy \& Salvetti, 2005), and components of the host cell DNA replication machinery (Nash et al., 2009). Viral replication takes place in the nucleus, where cellular proteins, including RPA, colocalize with viral proteins in replication centers (Stracker et al., 2004). AAV replication in the presence of minimal Ad helper proteins induces a robust DDR-like response. This response is independent of the MRN complex and seems to be mediated principally by DNA-PKcs and, to a lesser extent, by ATM (Collaco et al., 2009; Schwartz et al., 2009). The response involves the accumulation of DNA-PK in compartments in which viral replication is occurring, and the pan-nuclear phosphorylation, not only of H2AX, but also of Smc1 and ATM (Schwartz et al., 2009). In another study, the phosphorylation of RPA, Nbs1 and Chk1/2 was observed, but the phosphorylation pattern was not investigated (Collaco et al., 2009).

In addition to the DNA-PK-dependent DDR induced by AAV replication, studies on recombinant AAV (rAAV) vectors (Carter, 2004), have demonstrated the existence of a requirement for DNA-PKcs and Ku70/80 for viral DNA replication (Choi et al., 2010). The inactivation of DNA-PK by a DNA-PK inhibitor or siRNA significantly decreases the replication of rAAV, and any rAAV DNA that is replicated forms head-to-head or tail-to-tail 
junctions. Moreover, AAV-ITRs interact directly with $\mathrm{Ku}$ proteins, suggesting that viral DNA is recognized directly by cellular NHEJ factors (Choi et al., 2010). Furthermore, DNA-PKcs and Artemis have been shown to open the ITR hairpin loops of rAAV in vivo, in a tissue-dependent manner. In the absence of either of these factors, double-stranded linear rAAV genomes capped with covalently closed hairpins at their termini accumulate in cells (Inagaki et al., 2007), confirming the importance of host cell NHEJ proteins for viral DNA end processing. By contrast to the "hyperactivation" of DNA-PK observed in response to replicating $\mathrm{AAV}$, the DNA of UV-inactivated AAV particles activates a DDR involving ATM and ATR, leading to the inhibition of cell cycle progression (Jurvansuu et al., 2005). It has been suggested that the UV-treated DNA mimics stalled replication forks (Jurvansuu et al., 2005), whereas DNA-PK activation is consistent with the presence of DSBs as intermediate products during AAV replication.

DNA-PKcs and Ku70/80 as well as other cellular repair or replication factors including Topoisomerases I and II, MSH2-MSH6, RecQL, PARP and scaffold attachment factor A (SAF-A) are involved in Kaposi's sarcoma-associated herpesvirus (KSHV) lytic replication (Wang et al., 2008). KSHV is a large dsDNA virus and the etiologic agent of several AIDS-associated cancers, including Kaposi's sarcoma (Antman \& Chang, 2000). The lytic replication of KSHV and the continuous primary infection of fresh cells are responsible for viral tumorigenicity and pathogenesis, by contrast to what has been reported for other oncogenic viruses (Grundhoff \& Ganem, 2004). The proteins listed above bind to KSHV DNA fragments and accumulate in viral replication compartments in the nucleus, suggesting a possible role for these host replication and repair proteins in the viral lytic replication process (Wang et al., 2008).

In the case of infection with herpes simplex virus type 1 (HSV-1), which contains a linear dsDNA molecule, a DNA damage signaling is induced which depends principally on ATR (Lilley et al., 2005; Wilkinson \& Weller, 2006). Several members of the cellular DNA damage-sensing machinery, including RPA, RAD51 and Nbs1, are activated and redistributed during viral DNA replication, indicating that infection induces the host response to DNA damage. H2AX is phosphorylated but the $\gamma-\mathrm{H} 2 \mathrm{AX}$ signal is marginalized to the periphery of viral replication centers (Wilkinson \& Weller, 2006). HSV-1 sequesters hyperphosphorylated RPA away from viral replication compartments, thus preventing a normal ATR-signaling response. The partial and mislocalized activation of the cellular DDR leads ultimately to its disorganization.

ATR is also activated during viral replication of the dsDNA virus human cytomegalovirus (HCMV), leading to an induction of $\gamma-\mathrm{H} 2 \mathrm{AX}$ (Luo et al., 2007). Contrary to what has been observed for HSV-1, $\gamma-\mathrm{H} 2 \mathrm{AX}$ co-localizes with viral replication compartments during late-stage infections with HCMV. Only a subset of proteins in addition to $\gamma-\mathrm{H} 2 \mathrm{AX}$ was specifically sequestered in viral replication centers, with other proteins excluded from these centers, impeding both the efficient repair of viral DNA and checkpoint activation (Luo et al., 2007).

ATM-dependent checkpoint signaling takes place during induction of Epstein Barr virus lytic replication (Kudoh et al., 2005) or polyomavirus replication (Dahl et al., 2005). This is accompanied by the phosphorylation of a number of DNA damage markers including H2AX. The cellular ATM activation in response to both viruses leads to a prolonged S-phase advantageous for viral lytic replication. However, both viruses have developed efficient strategies to block ATM-induced p53 downstream signaling that would eventually lead to 
apoptosis (Dahl et al., 2005; Kudoh et al., 2005). By contrast, the autonomous minute virus of canines (MVC), a member of the parvovirus family, induces apoptosis and G(2)/M-phase arrest in infected canine cells (Chen et al., 2010). This seems to be the result of the induction of an ATM/p53-mediated DDR (Luo et al., 2011). Infected cells display phosphorylation of H2AX, RPA, ATM and ATR. The inhibition or knockdown of ATM decreased cell death and reduced MVC DNA replication.

In summary, studies of the response of the cell to viral genomic material have demonstrated that the activation of a damage response involving ATM (e.g. in the case of MVC) or ATR (UV-inactivated rAAV) leads to cell cycle arrest or p53-dependent cell death, unless downstream effectors are inactivated or sequestered by viral proteins (HSV-1, HCMV). By contrast, DNA-PK activation (Ad, AAV) leads to pan-nuclear H2AX phosphorylation, which does not seem to be detrimental to the cell. These findings have possible consequences for the choice of viral vectors for gene targeting. It remains to be determined whether the "ectopic" phosphorylation of DNA-PK downstream targets affects the stability of the host cell genome or impairs DNA repair in infected cells. It has also been shown that the specific recruitment of a subset of cellular DNA repair factors is essential for viral DNA replication, suggesting that inhibitors targeting these proteins may have antiviral activity.

\subsubsection{DNA damage signals induced by retroviruses}

Interaction with the cellular DNA damage sensing machinery is not limited to DNA viruses. Retroviruses, which contain a single-stranded RNA genome, use a viral-encoded reverse transcriptase to generate a cDNA that is then integrated into the host genome. The preintegration complex contains the cDNA and the viral-encoded integrase enzyme. This enzyme then mediates strand transfer to integrate the viral DNA into the host DNA in a non site-specific fashion (Weitzman et al., 2004). The interaction of retroviruses with the cellular DNA repair machinery has been studied in detail (Lilley et al., 2007; Sakurai et al., 2009; Skalka \& Katz, 2005). The NHEJ pathway has been implicated in the sensing and processing of the linear cDNA, although the exact step of the viral life-cycle affected by the cellular DNA repair machinery remains unclear Ariumi et al. (2005). It is possible that the viral cDNA acts directly as a substrate for NHEJ, which circularizes the DNA by end ligation (Li et al., 2001). The circularization of unintegrated DNA in this context may protect the viral DNA from degradation and the cell from apoptosis (Kilzer et al., 2003). Consistent with this hypothesis, the infection with retrovirus of cells lacking NHEJ factors results in apoptosis, suggesting that DNA-PKcs and Ku70/80 may protect against the cellular toxicity of high levels of retroviral cDNA (Li et al., 2001).

Another interaction of retroviruses with the DNA repair machinery is constituted by the role of cellular repair and damage signaling factors in the integration of viral DNA into the host genome (Daniel et al., 1999). During retroviral integration, DSBs are created as an intermediate that may be detected as DNA damage by the host cell (Sakurai et al., 2009). Transient phosphorylation of histone H2AX occurs at retroviral integration sites, and it has been suggested that the completion of the integration process is dependent on DNA-PK (Daniel et al., 1999; 2004). DNA-PK-deficient mouse scid cells infected with three different retroviruses display much lower levels of DNA integration than wild-type cells and die by apoptosis. Furthermore, it has been reported that DNA-PKcs is required for efficient transduction by retroviral vectors (Daniel et al., 1999). Other PIKKs have since been shown to be activated after HIV-1 infection and to play a potential role in provirus integration. The use 
of caffeine or a small-molecule inhibitor to block the ATM activity results in the inhibition of HIV transduction and replication (Daniel et al., 2005; Lau et al., 2005).

DNA-PK and ATM also seem to be important for correct end processing at the junctions between HIV-1 provirus and host DNA (Sakurai et al., 2009). Large numbers of abnormal junctions are observed in Mre11- and DNA-PKcs-deficient cells, and Artemis-deficient cells also display such abnormalities, suggesting a role for NHEJ processing factors in correct viral integration. Another study has reported a role for $\mathrm{Ku} 70 / 80$ in the targeting of retroviral elements to chromatin domains prone to gene silencing. Higher levels of viral DNA expression are observed in the absence of $\mathrm{Ku} 70 / 80$, with no effect on viral transduction (Masson et al., 2007).

The importance of cellular components of the DDR for the replication of some viruses could be exploited for therapeutic purposes. For instance, a small-molecule ATM-inhibitor displayed antiviral activity in a proof-of-concept study with HIV-1, in which ATM deficiency sensitized cells to retrovirus-induced cell death (Lau et al., 2005).

\subsection{Tethering of repair factors}

Recent studies in yeast and mammals have demonstrated that it is not the DNA lesion that triggers the DDR, leading to the activation of transducer kinases, but the local concentration of signaling factors at repair foci. Soutoglou \& Misteli (2008) demonstrated that a DDR can be triggered in the absence of DNA lesions. The artificial localized tethering of repair factors was found to be sufficient to trigger a full DDR response, including cell-cycle arrest, in the absence of DNA breaks. Tethering was achieved by fusing repair proteins to the Escherichia coli lac repressor and expressing the resulting constructs in mouse NIH-3T3 cells containing multiple lacR binding sites, stably integrated into the genome (Soutoglou \& Misteli, 2008). The immobilization of Nbs1, Mre11 or MDC1 alone led to DDR activation. In addition, the tethering of ATM was sufficient to induce ATM kinase activity and autophosphorylation. Consistent with its function downstream from the MRN complex, the induction of ATM activity was not affected by an absence of Mre11 or Nbs1. As similar results were obtained in analogous experiments in Saccharomyces cerevisiae (Bonilla et al., 2008), the concentration of key factors on the chromatin may be considered a universal characteristic of DDR initiation and amplification in eukaryotes (Misteli \& Soutoglou, 2009). The tethering experiments may be seen as complementary to the experiments with siDNA described below, as the DNA break-mimicking DNA molecules are (i) too short for the formation of repair foci and (ii) not in a chromatin context.

\subsection{DDR induction by cofactors, oxidative stress or changes in chromatin state}

ATM, and consequently the DDR, can be activated in the absence of DNA breaks, by changes in chromatin structure. Bakkenist \& Kastan (2003) showed that ATM is rapidly activated by the exposure of cells to chromatin-active agents, such as mild hypotonic buffers, or treatment with chloroquine. Furthermore, histone deacetylase (HDAC) inhibitors, such as TSA, which induces the global decondensation of chromatin, can also induce ATM activity (Jang et al., 2010; Mazumdar et al., 2006). Consistent with its role as a sensor of chromatin structure, ATM can interact with the chromatin via the nucleosome-binding protein HMGN1 before DNA damage occurs. The loss of this interaction in the absence of HMGN1 compromises ATM activation in response to IR (Kim et al., 2009). 
ATM-dependent phosphorylation of H2AX during M-phase has been reported to occur in the absence of DNA damage (Ichijima et al., 2005; Mazumdar et al., 2006). The high degree of compaction of mitotic chromosomes may be the signal responsible for activating DNA damage signaling kinases in the absence of apparent DNA lesions (Ichijima et al., 2005).

Another recent study showed that DNA-damage signaling pathways and ATM could be activated directly by hypoxia, apparently in the absence of lesions (Bencokova et al., 2009). The direct mechanism involved is unknown, but the hypoxia-induced activation of ATM is independent of the MRN complex, and active, autophosphorylated ATM has a pan-nuclear rather than focal distribution. The activation of ATM signaling in response to hypoxia may account for the cessation of replication when oxygen levels are low.

ATM is a also a direct sensor of oxidative stress, in the absence of DNA lesions. Oxidation by ROS results in the formation of an active, disulfide-cross-linked, ATM dimer (Guo et al., 2010). The activation of ATM in response to oxidative stress is independent of the MRN complex and leads to the phosphorylation of DDR effectors including p53 and Chk2, but not the chromatin-associated proteins H2AX or Kap1. This confirms that ATM activation through oxidation may occur without the involvement of the DNA damage recognition machinery. Consistent with ATM activation, the transducer kinase ATR can also be activated in the absence of DNA damage. Toledo et al. (2008) reported the ectopic activation of ATR following overproduction of a fragment of TopBP1 containing a domain known to stimulate ATR kinase activity (Kumagai et al., 2006). ATR activation was sufficient to drive cell cycle arrest and senescence.

\subsection{Systemic response to foreign DNA}

DNA fragments trigger a DDR at the cellular level, but the detection of foreign DNA by specific sensors can trigger an innate immune response at the systemic level (for review see Vilaysane \& Muruve (2009), Yanai et al. (2009) and Rathinam \& Fitzgerald (2011)). The innate immune system is an integral part of the host response to viral and bacterial intrusion. Its activation leads to diverse cellular responses, including the induction of interferon regulatory factors (IRF) 3 and 7, which regulate the production of type I interferon. Furthermore, NFkB is induced, and regulates the expression of pro-inflammatory cytokines (Vilaysane \& Muruve, 2009). We provide here a brief overview of the principal sensors of foreign DNA found in humans.

Bacterial DNA differs from mammalian DNA principally in terms of its high CpG dinucleotide content. Furthermore, most of the small number of $\mathrm{CpG}$ dinucleotides present in mammalian DNA are methylated, whereas the CPG dinucleotides in bacterial DNA are generally unmethylated (Hemmi et al., 2000). The activation of innate immune responses by nucleic acids is mediated by transmembrane Toll-like receptors (TLRs) and cytosolic receptors. The best understood sensor of microbial DNA is TLR9, which is found principally in plasmacytoid dendritic cells (pDCs) in humans (Hemmi et al., 2000; Wagner, 2004). The endosomal uptake of CpG DNA activates TLR9, which binds MyD88, IRAK4 and IRAK1 that are required for the activation of $\mathrm{NF} \kappa \mathrm{B}$ and the induction of type I interferons via IRF7 (Akira et al., 2006; Vilaysane \& Muruve, 2009). Several studies have also shown that, in addition to responding to bacterial DNA, TLR9 plays an important role in host defense against viruses, including DNA viruses such as herpes simplex virus and murine cytomegalovirus (Delale et al., 2005; Lund et al., 2003). 
In addition to the membrane-bound TLR9, cytosolic DNA sensors have recently been identified (Yanai et al., 2009). These sensors include TREX1, DNA-dependent activator of interferon regulatory factors (DAI) and a DNA-sensing inflammasome containing absent in melanoma 2 (AIM2). This protein belongs to the HIN-200 family and is a cytoplasmic sensor mediating caspase 1 activation in response to cytoplasmic dsDNA (Burckstummer et al., 2009; Fernandes-Alnemri et al., 2009; Hornung et al., 2009). Another cytosolic DNA sensor and activator of innate immune responses, DAI (also known as DLM-1 and Z-DNA binding protein 1), has also recently been identified (Takaoka et al., 2007). DAI binds dsDNA, leading to its association with the IRF3 transcription factor and the TBK1 serine/threonine kinase, resulting in a signaling cascade that culminates in $\mathrm{NF} \kappa \mathrm{B}$ activation. The activation of interferon responses is restricted by the length of the DNA, with little activation observed in response to DNA molecules of less than $100 \mathrm{bp}$ in length, suggesting that DAI activation requires the formation of a multimeric complex over long stretches of DNA (Takaoka \& Taniguchi, 2008).

Several studies have identified the $3^{\prime} \rightarrow 5^{\prime}$ DNA exonuclease DNaseIII/TREX1 as associated with autoimmune and inflammatory diseases in humans (Crow et al., 2006; Lee-Kirsch et al., 2007). TREX1 is a regulator of DNA homeostasis in the cell and has been reported to counteract the activation of ATM by small ssDNA fragments (section 3.1). Indeed, in the absence of TREX1, 60-65 bp ssDNA polynucleotides accumulate, leading to chronic ATM-dependent DNA damage checkpoint signaling (Yang et al., 2007). Thus, TREX1 is not itself a DNA sensor. Instead, it regulates the accumulation of the ssDNA that can trigger an innate immune response. In addition to linking a DDR factor to the immune response, these findings demonstrate that immune responses may be triggered not only by foreign DNA, but also by self-derived DNA.

The most prominent protein involved in both the DDR and the immune response, in addition to TREX1, is DNA-PKcs. In addition to its long known role in V(D)J recombination in developing lymphocytes (Jeggo et al., 1995), DNA-PKcs has also been reported to phosphorylate IFN regulatory factor-3 (IRF-3) directly (Karpova et al., 2002). IRF-3 plays a key role in the host response to viral infection, and its phosphorylation by DNA-PK after viral infection results in its nuclear retention and delayed proteolysis. Another study has suggested that DNA-PKcs mediates Akt activation in response to CpG-DNA in bone marrow-derived macrophages (BMDMs) (Dragoi et al., 2005). In BMDMs, DNA-PKcs associates with Akt upon CpG-DNA stimulation, thereby triggering the nuclear translocation of Akt. It has been suggested that TLR9 is involved in this pathway, but its possible role remains a matter of debate (Dragoi et al., 2005; Sester et al., 2006). The CpG-DNA/DNAPKcs / Akt pathway may account for the induction, by CpG-DNA and synthetic CpG oligonucleotides, of prosurvival signals delivered to the immune system (Dragoi et al., 2005; Park et al., 2002).

\section{Signal interfering DNA (siDNA)}

As summarized in Figures 1 and 2, difficulties attributing the activation of a specific transducer to a specific type of damage in vivo result principally from the multiple type of damage induced by a single treatment, through the mechanism of action of the treatment and metabolism of the initial damage through replication and repair. Moreover, the large DNA molecules sometimes used to induce a damage response (see section 3.1) probably contain sequences recognized by specific proteins that may interfere with DNA damage recognition 
and repair. We recently tried to overcome these problems by proposing the use of a new class of small molecules (siDNA, for small interfering DNA) each mimicking one particular type of damage and are not degraded, replicated or repaired in the cell.

\subsection{SiDNA: principle and properties}

We initially designed and tested only a few classes of siDNA molecules, to provide proof-of-concept for this approach. However, this concept can be extended to any specific type of damage. An siDNA is a small nucleic acid molecule carrying a modification recognized as a lesion by the sensor and transducer proteins. In addition to mimicking a specific type of damage, siDNA molecules must (i) be resistant to the action of nucleases, (ii) be as small as possible, to minimize the formation of secondary structures or degradation products, (iii) have no specific sequence likely to be recognized by DNA-binding proteins, such as transcription factors, (iv) mimic one single type of damage, ideally one that cannot be processed and (v) be recognized by at least one molecule involved in the DDR. SiDNAs are oligonucleotides chemically synthesized on solid support, by cycles of nucleotide addition. They are protected from exonuclease degradation by three phosphorothioate groups at the free $3^{\prime}$ and $5^{\prime}$ ends. Most siDNA molecules are double-stranded and have a specific modification characteristic of one type of damage. Dissociation of the short duplex is prevented by a linker tethering the two complementary strands at one or both ends of the molecule. The linker molecule

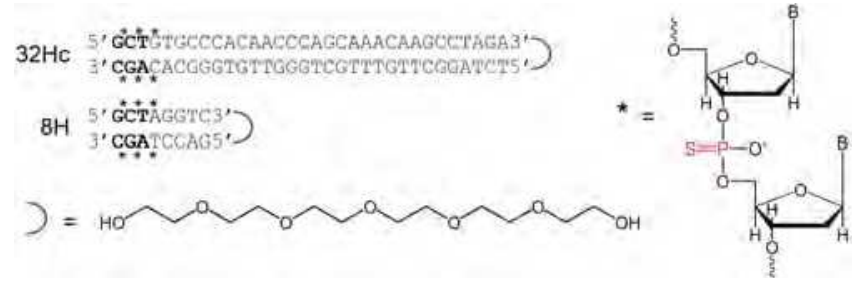

Fig. 4. Structure of the DSB-mimicking Dbait. Dbait 32Hc is a $32 \mathrm{bp}$ DNA molecule tethered to its complementary sequence by a hexaethylene glycol loop (blue half circle) at one end and protected against exonuclease by phosphorothioate nucleotides (asterisks, phosphorothioate bond highlighted in red) at the other end. In the name 32Hc, $\mathrm{H}$ stands for hexaethylene glycol and c refers to the sequence. The sequence is not important for recognition as a DSB. The corresponding negative control, $8 \mathrm{H}$, has the same basic structural features as $32 \mathrm{Hc}$, but is too short to bind the central NHEJ components. B, base.

consists of a polyethylene glycol chain that is inert and stable in living systems. The resulting molecules are very stable, with melting temperatures of about 85 to $90^{\circ} \mathrm{C}$, despite their small size (between 16 and $64 \mathrm{bp}$ ). They are resistant to incubation for six hours with serum or cell extract (unpublished data). Like most nucleic acid-based molecules, siDNAs penetrate cells poorly and complexing with transfection agents (Patil et al., 2005) or lipophilic molecules (Rossi, 2004) is required for efficient entry. Three classes of molecules have already been tested: molecules mimicking double-strand breaks (Dbait), molecules mimicking single-strand breaks (Pbait) and molecules mimicking single-strand DNA stretches (Sbait). An example of the structure of a Dbait molecule is provided in Figure 4. Every siDNA is recognized by specific sensors and triggers a corresponding partial DDR. 


\subsection{SiDNAs induce specific, stable and persistent damage responses}

PIKKs and PARP enzymes are thought to be the first transducers activated by DNA damage. We threfore monitored the cellular response induced by siDNAs by detecting the modification of the downstream targets of these enzymes in cells. Using mutant cells defective in the various enzymes, we showed that Dbait activated DNA-PK and PARP, Pbait activated only PARP and Sbait activated only ATM ((Quanz et al., 2009b); to be published). These transducer activations resulted in the posttranslational modification of all known targets of these enzymes investigated. For example, Dbait induces the phosphorylation of H2AX, RPA, p53, Nbs1, Chk1, Chk2, DNA-PK, ATM, Hsp90 $\alpha$, and the PARylation of a broad number of proteins. Interestingly, ATM which is also thought to be activated by DSBs, was not activated by Dbait or Pbait, but exclusively by Sbait molecules, which are single-stranded. This is consistent with the model in which DSBs must be partially degraded to activate ATM, as described above. The association of Mre11 with Rad50 and Nbs1 stimulates its endonuclease and exonuclease activities, resulting in the processing of DSB ends, leading to the generation of overhanging ssDNA regions (Paull \& Gellert, 1998; 1999). Our results show that DSBs do not directly activate ATM if they remain unprocessed.

The posttranslational modifications induced by the siDNA-mediated activation of transducers persist for more than 24 hours in the cells. Phosphorylated or PARylated effectors have been detected more than one day after treatment and their persistence in cells depends on the turnover rate of the modified protein and the rate of cell division (Quanz et al., 2009b). Phosphorylated histone H2AX, for instance, was detected up to five days after treatment with Dbait, when Dbait molecules were no longer present in the cell. Similar results were obtained for other effectors, suggesting that siDNAs do not induce feedback control mechanisms ensuring the rapid return of cells to an "unactivated" state when repair is completed. At least three phosphatases, protein phosphatase 2A (PP2A), wild-type p53-induced phosphatase (Wip1) and protein phosphatase 5 (PP5), are involved in the DDR. It remains unclear how these phosphatases are activated during DDR, but they are instrumental in ATM activation (Ali et al., 2004; Goodarzi et al., 2004; Shreeram et al., 2006). The results of studies of unrepairable siDNAs suggest that the phosphatases or the proteasome must be activated by a "successful repair" signal instead, rather than simply removing phosphates or the modified proteins as a part of an equilibrium.

\subsection{Transducer activation by siDNA is not sufficient to induce complete DDR}

Although transducers are fully activated and all their molecular targets seem to be modified, the siDNAs Dbait and Pbait do not trigger the major end-points of the DDR response: cell-cycle arrest and apoptosis. In the absence of genotoxic or other stresses, cells with strong siDNA responses continue to divide at the same rate as untreated cells and do not enter apoptosis (Quanz et al., 2009b). This suggests that the DDR requires a correct spatio-temporal organization and/or more than a single damage signaling input for full execution. This is consistent with the model described above, in which redundant pathways may control the risk of erroneous signaling in cells (Yarosh, 2001). According to this hypothesis, the signal resulting from one siDNA treatment would not be sufficient to trigger a complete DDR response.

SiDNAs also differ from chromosomal DNA damage in their location and the timing of the different activation processes. SiDNAs constitute an artificial form of damage outside the context of chromatin and able to cross the cytoplasm, which contains a subset of effectors and transducers, such as DNA-PK and PARP. These signaling enzymes are therefore activated in 
the cytoplasm and modify the targets present in this compartment (Quanz et al., submitted, Figure 5). The lack of coordination of target modifications at the site of DNA damage prevents

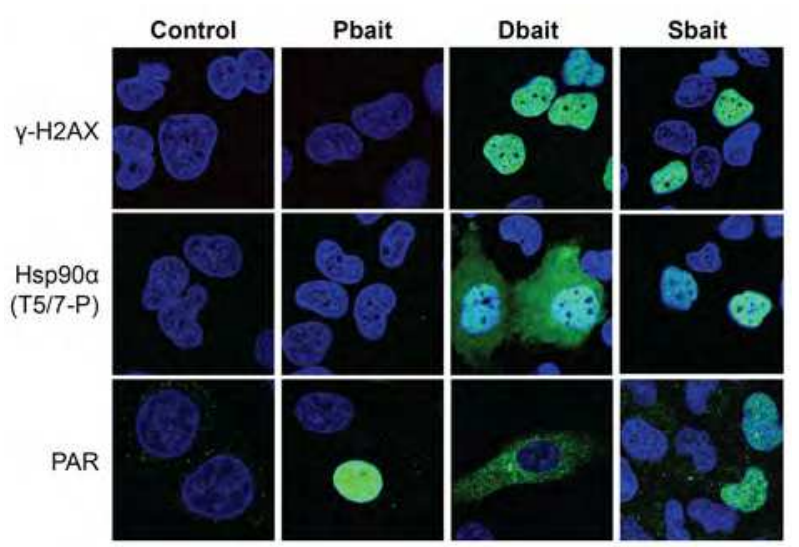

Fig. 5. Differential cytoplasmic and nuclear transducer activation by different siDNAs. Both Dbait and Sbait treatment lead to the phosphorylation of H2AX (green, top) and Hsp90 $\alpha$ (green, middle) and induce a PARylation signal (green, bottom). Unlike Sbait, Dbait is already recognized in the cytoplasm, inducing cytoplasmic Hsp90 $\alpha$ phosphorylation and a cytoplasmic PARylation signal. Pbait, which activates only PARP, induces PARylation but not the phosphorylation of $\mathrm{H} 2 \mathrm{AX}$ or Hsp90 $\alpha$. The negative control is an siDNA molecule that is too short to recruit and activate DNA damage transducers. The cell nuclei are shown in blue.

the further accumulation of DNA repair proteins at repair foci at these sites (Quanz et al., 2009b). For example, in cells treated with Dbait, DNA-PK autophosphorylation is detected in both the cytoplasm and the nucleus and H2AX is phosphorylated along the length of the chromosome. After the irradiation of Dbait-treated cells, repair proteins, such as Nbs1, 53BP1, Rad51, do not relocate to sites of damage or form repair foci. However, despite their incapacity to form repair foci, irradiated siDNA-treated cells display a complete DDR response, with the induction of apoptosis (Quanz et al., 2009b).

\subsection{SiDNAs inhibit DNA repair}

The disturbance of the spatiotemporal organization of the DDR by siDNA leads to inhibition of the formation of repair foci after irradiation. Cells treated with Dbait or Pbait are therefore sensitive to IR or other DNA damaging agents. Irradiated DNA is repaired with two-component kinetics. Most of the damage is repaired rapidly, with no significant effect of Dbait treatment. By contrast, the repair of the residual damage (15-20\%), which takes longer, is strongly affected by Dbait treatment (Quanz et al., Figure 6). The slowly repaired damage is thought to correspond to DSBs with complex ends (Riballo et al., 2004) and/or to be predominantly located at the periphery of genomic heterochromatin, in regions of condensed chromatin (Goodarzi et al., 2010; Mosesso et al., 2010). As a consequence of the inhibition of repair, cells treated with Dbait are highly sensitive to irradiation. This property has been used in vivo in the development of new drugs for treating radioresistant tumors. DT01, a clinical product from the Dbait class of siDNAs, increases the survival of nude mice xenografted with radioresistant melanoma (Quanz et al., 2009a). DT01 efficacy is strictly dependent on the dose 


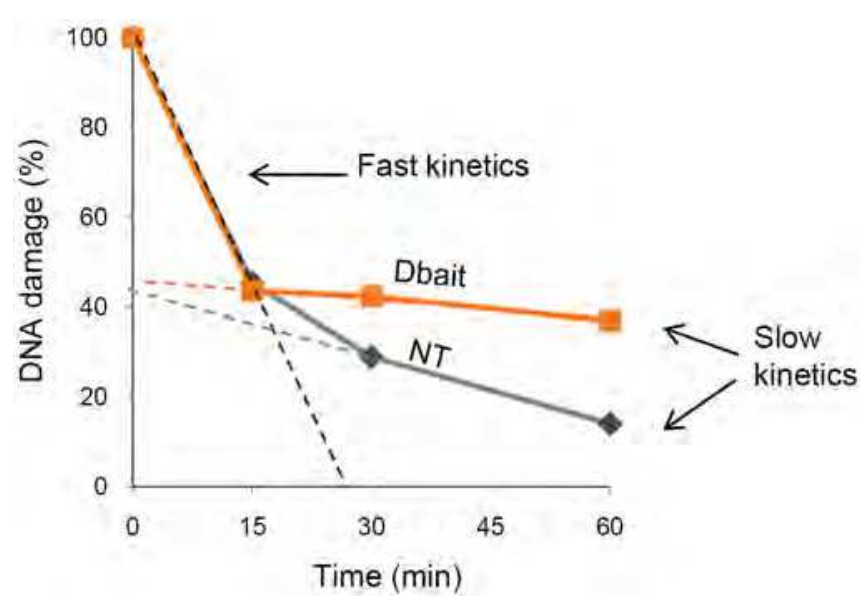

Fig. 6. Dbait inhibits slow DNA repair. MRC5 cells transfected or not transfected with Dbait were irradiated with $8 \mathrm{~Gy}$. DNA damage repair was followed by alkaline comet assays over a period of $60 \mathrm{~min}$.

administered (Figure 7) and is independent of the associated radiotherapy protocol. A phase I/II clinical trial will be initiated in 2011, to assess the efficacy of a treatment combining DT01 and radiotherapy for the treatment of local metastases of melanoma.

\section{Conclusion}

The study of DNA repair is a complicated task, due to the diversity of damage induced by DNA-damaging agents and the subsequent conversion of the damage by repair pathways or the DNA replication machinery. Furthermore, the damage may be repaired by different repair pathways, depending on the phase of the cell cycle at the time of damage. Finally, if the damage to the chromosome is too extensive, the cell undergoes apoptosis or senescence. The use of different techniques to induce a specific type of damage in the absence of chromosomal DNA damage within the cell has greatly contributed to our understandings of individual repair pathways. The tethering of repair proteins has demonstrated that the local concentration of damage signaling factors is sufficient to trigger a full damage response, independently of the presence of actual cellular damage. Consistent with this, agents modifying chromatin topology can induce DNA damage transducer activity in the absence of DNA lesions. Studies of the recognition of viral genomic material have contributed to our understanding of the cellular DDR. For example, studies of adenovirus interference with damage signaling through degradation of the MRN complex have suggested that MRN plays an upstream role in damage detection. Synthetic ICL constructs, introduced into cells on plasmids, have proved a useful tool for investigating this specific type of DNA damage. This approach made it possible to demonstrate the contribution of the Fanconi anemia pathway to the repair of ICLs. Studies based on the use of DNA fragments have identified ssDNA as the universal signal of the ATM-induced DDR. The introduction into cells of small double-stranded siDNA molecules, which are resistant to exonuclease attack and repair, has made it possible to demonstrate that DSBs alone activate DNA-PK only, leading to the phosphorylation of a multitude of downstream targets. However, unlike 


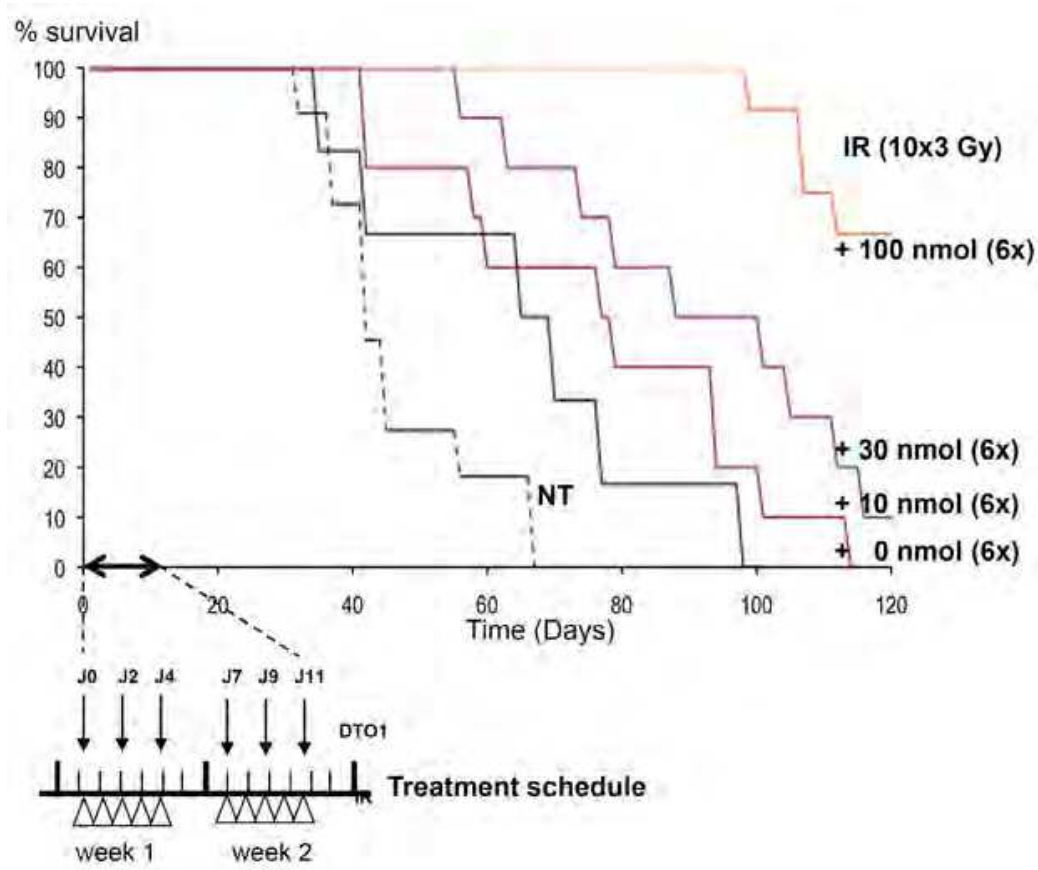

Fig. 7. The survival of xenografted animals is dependent on DT01 dose. Kaplan-Meier representation of the survival of nude mice with xenografted SK28 melanoma tumors. After two weeks of treatment, consisting of six injections of DT01 injections (arrows) at various doses and the administration of $3 \mathrm{~Gy}$ in 10 fractions (triangles, tumor volume was assessed. The ethical limit for tumor volume was $2000 \mathrm{~mm}^{3}$. NT: untreated control group.

ATM activation by ssDNA, DNA-PK activation has a much smaller impact on the cell cycle and apoptosis induction. Thus, siDNA can be used as a tool for the specific activation of individual repair signaling enzymes, making it possible to investigate specific branches of the damage response, which is not possible with conventional DNA damaging agents that induce a plethora of different lesions. A similar approach could now be used for other kinds of DNA damage, to check for activation of the corresponding downstream repair pathways in cells. This should make it possible to answer currently unresolved questions, concerning the impact of PARP-signaling or mismatch-signaling on cell fate, for example. This should not only deepen our understanding of the specific pathways activated in response to a particular type of damage, but should also be useful in cancer treatment. The "jamming" of specific repair signaling pathways may help to overcome resistance to treatment and to enhance the response to cancer treatments targeting DNA.

\section{Acknowledgments}

We apologize to the many groups whose primary research papers could not be cited owing to space constraints. Work in the authors' laboratory was supported by Institut Curie, CNRS, INSERM, and ANR grant ANR-08-Biot-009-02. 


\section{References}

Ahnesorg, P., Smith, P. \& Jackson, S. P. (2006). XLF interacts with the XRCC4-DNA ligase iv complex to promote DNA nonhomologous end-joining, Cell 124(2): 301-13.

Akira, S., Uematsu, S. \& Takeuchi, O. (2006). Pathogen recognition and innate immunity, Cell 124(4): 783-801.

Ali, A., Zhang, J., Bao, S., Liu, I., Otterness, D., Dean, N. M., Abraham, R. T. \& Wang, X. F. (2004). Requirement of protein phosphatase 5 in DNA-damage-induced ATM activation, Genes Dev 18(3): 249-54.

Antman, K. \& Chang, Y. (2000). Kaposi's sarcoma, N Engl J Med 342(14): 1027-38.

Ariumi, Y., Turelli, P., Masutani, M. \& Trono, D. (2005). DNA damage sensors ATM, ATR, DNA-pkcs, and parp-1 are dispensable for human immunodeficiency virus type 1 integration, J Virol 79(5): 2973-8.

Audebert, M., Salles, B. \& Calsou, P. (2004). Involvement of poly(adp-ribose) polymerase-1 and $x$ rcc1/DNA ligase iii in an alternative route for DNA double-strand breaks rejoining, J Biol Chem 279(53): 55117-26.

Bailone, A., Brandenburger, A., Levine, A., Pierre, M., Dutreix, M. \& Devoret, R. (1984). Indirect sos induction is promoted by ultraviolet light-damaged minif and requires the minif lyna locus, J Mol Biol 179(3): 367-90.

Bakkenist, C. J. \& Kastan, M. B. (2003). DNA damage activates ATM through intermolecular autophosphorylation and dimer dissociation, Nature 421(6922): 499-506.

Bandaru, V., Sunkara, S., Wallace, S. S. \& Bond, J. P. (2002). A novel human DNA glycosylase that removes oxidative DNA damage and is homologous to escherichia coli endonuclease viii, DNA Repair (Amst) 1(7): 517-29.

Bartek, J. \& Lukas, J. (2003). Chk1 and chk2 kinases in checkpoint control and cancer, Cancer Cell 3(5): 421-9.

Bekker-Jensen, S., Lukas, C., Kitagawa, R., Melander, F., Kastan, M. B., Bartek, J. \& Lukas, J. (2006). Spatial organization of the mammalian genome surveillance machinery in response to DNA strand breaks, J Cell Biol 173(2): 195-206.

Bencokova, Z., Kaufmann, M. R., Pires, I. M., Lecane, P. S., Giaccia, A. J. \& Hammond, E. M. (2009). ATM activation and signaling under hypoxic conditions, Mol Cell Biol 29(2): 526-37.

Bianchi, V., Pontis, E. \& Reichard, P. (1986). Changes of deoxyribonucleoside triphosphate pools induced by hydroxyurea and their relation to DNA synthesis, J Biol Chem 261(34): 16037-42.

Bianco, P. R., Tracy, R. B. \& Kowalczykowski, S. C. (1998). DNA strand exchange proteins: a biochemical and physical comparison, Front Biosci 3: D570-603.

Boiteux, S. \& Radicella, J. P. (2000). The human ogg1 gene: structure, functions, and its implication in the process of carcinogenesis, Arch Biochem Biophys 377(1): 1-8.

Bonilla, C. Y., Melo, J. A. \& Toczyski, D. P. (2008). Colocalization of sensors is sufficient to activate the DNA damage checkpoint in the absence of damage, Mol Cell 30(3): 267-76.

Bonner, W. M., Redon, C. E., Dickey, J. S., Nakamura, A. J., Sedelnikova, O. A., Solier, S. \& Pommier, Y. (2008). Gammah2ax and cancer, Nat Rev Cancer 8(12): 957-67.

Bouchard, V. J., Rouleau, M. \& Poirier, G. G. (2003). Parp-1, a determinant of cell survival in response to DNA damage, Exp Hematol 31(6): 446-54. 
Brachman, E. E. \& Kmiec, E. B. (2002). The 'biased' evolution of targeted gene repair, Curr Opin Mol Ther 4(2): 171-6.

Brown, K. E. (2010). The expanding range of parvoviruses which infect humans, Rev Med Virol 20(4): 231-44.

Brown, K. L., Roginskaya, M., Zou, Y., Altamirano, A., Basu, A. K. \& Stone, M. P. (2010). Binding of the human nucleotide excision repair proteins $x p a$ and $x p c / h r 23 b$ to the $5 r$-thymine glycol lesion and structure of the cis- $(5 r, 6 s)$ thymine glycol epimer in the 5'-gtgg-3' sequence: destabilization of two base pairs at the lesion site, Nucleic Acids Res 38(2): 428-40.

Buck, D., Malivert, L., de Chasseval, R., Barraud, A., Fondaneche, M. C., Sanal, O., Plebani, A., Stephan, J. L., Hufnagel, M., le Deist, F., Fischer, A., Durandy, A., de Villartay, J. P. \& Revy, P. (2006). Cernunnos, a novel nonhomologous end-joining factor, is mutated in human immunodeficiency with microcephaly, Cell 124(2): 287-99.

Burckstummer, T., Baumann, C., Bluml, S., Dixit, E., Durnberger, G., Jahn, H., Planyavsky, M., Bilban, M., Colinge, J., Bennett, K. L. \& Superti-Furga, G. (2009). An orthogonal proteomic-genomic screen identifies aim2 as a cytoplasmic DNA sensor for the inflammasome, Nat Immunol 10(3): 266-72.

Cadet, J., Berger, M., Douki, T. \& Ravanat, J. L. (1997). Oxidative damage to DNA: formation, measurement, and biological significance, Rev Physiol Biochem Pharmacol 131: 1-87.

Carson, C. T., Schwartz, R. A., Stracker, T. H., Lilley, C. E., Lee, D. V. \& Weitzman, M. D. (2003). The mre11 complex is required for ATM activation and the $\mathrm{g} 2 / \mathrm{m}$ checkpoint, EMBO J 22(24): 6610-20.

Carter, B. J. (2004). Adeno-associated virus and the development of adeno-associated virus vectors: a historical perspective, Mol Ther 10(6): 981-9.

Chan, K. K., Zhang, Q. M. \& Dianov, G. L. (2006). Base excision repair fidelity in normal and cancer cells, Mutagenesis 21(3): 173-8.

Chapman, J. D., Reuvers, A. P., Borsa, J. \& Greenstock, C. L. (1973). Chemical radioprotection and radiosensitization of mammalian cells growing in vitro, Radiat Res 56(2): 291-306.

Chappell, C., Hanakahi, L. A., Karimi-Busheri, F., Weinfeld, M. \& West, S. C. (2002). Involvement of human polynucleotide kinase in double-strand break repair by non-homologous end joining, EMBO J 21(11): 2827-32.

Chaurushiya, M. S. \& Weitzman, M. D. (2009). Viral manipulation of DNA repair and cell cycle checkpoints, DNA Repair (Amst) 8(9): 1166-76.

Chen, A. Y., Luo, Y., Cheng, F., Sun, Y. \& Qiu, J. (2010). Bocavirus infection induces mitochondrion-mediated apoptosis and cell cycle arrest at $\mathrm{g} 2 / \mathrm{m}$ phase, J Virol 84(11): 5615-26.

Chen, B. P., Uematsu, N., Kobayashi, J., Lerenthal, Y., Krempler, A., Yajima, H., Lobrich, M., Shiloh, Y. \& Chen, D. J. (2007). Ataxia telangiectasia mutated (ATM) is essential for DNA-pkcs phosphorylations at the thr-2609 cluster upon DNA double strand break, J Biol Chem 282(9): 6582-7.

Chen, J., Silver, D. P., Walpita, D., Cantor, S. B., Gazdar, A. F., Tomlinson, G., Couch, F. J., Weber, B. L., Ashley, T., Livingston, D. M. \& Scully, R. (1998). Stable interaction between the products of the BRCA1 and BRCA2 tumor suppressor genes in mitotic and meiotic cells, Mol Cell 2(3): 317-28. 
Choi, Y. K., Nash, K., Byrne, B. J., Muzyczka, N. \& Song, S. (2010). The effect of DNA-dependent protein kinase on adeno-associated virus replication, PLoS One 5(12): e15073.

Cleaver, J. E. (2005). Cancer in xeroderma pigmentosum and related disorders of DNA repair, Nat Rev Cancer 5(7): 564-73.

Collaco, R. F., Bevington, J. M., Bhrigu, V., Kalman-Maltese, V. \& Trempe, J. P. (2009). Adeno-associated virus and adenovirus coinfection induces a cellular DNA damage and repair response via redundant phosphatidylinositol 3-like kinase pathways, Virology 392(1): 24-33.

Cornelis, J. J., Su, Z. Z. \& Rommelaere, J. (1982). Direct and indirect effects of ultraviolet light on the mutagenesis of parvovirus h-1 in human cells, EMBO J 1(6): 693-9.

Costanzo, V., Paull, T., Gottesman, M. \& Gautier, J. (2004). Mre11 assembles linear DNA fragments into DNA damage signaling complexes, PLoS Biol 2(5): E110.

Craig, N. L. \& Roberts, J. W. (1981). Function of nucleoside triphosphate and polynucleotide in escherichia coli reca protein-directed cleavage of phage lambda repressor, J Biol Chem 256(15): 8039-44.

Crow, Y. J., Hayward, B. E., Parmar, R., Robins, P., Leitch, A., Ali, M., Black, D. N., van Bokhoven, H., Brunner, H. G., Hamel, B. C., Corry, P. C., Cowan, F. M., Frints, S. G., Klepper, J., Livingston, J. H., Lynch, S. A., Massey, R. F., Meritet, J. F., Michaud, J. L., Ponsot, G., Voit, T., Lebon, P., Bonthron, D. T., Jackson, A. P., Barnes, D. E. \& Lindahl, T. (2006). Mutations in the gene encoding the $3^{\prime}-5^{\prime}$ DNA exonuclease trex1 cause aicardi-goutieres syndrome at the ags1 locus, Nat Genet 38(8): 917-20.

Dahl, J., You, J. \& Benjamin, T. L. (2005). Induction and utilization of an ATM signaling pathway by polyomavirus, J Virol 79(20): 13007-17.

Daniel, R., Katz, R. A. \& Skalka, A. M. (1999). A role for DNA-PK in retroviral DNA integration, Science 284(5414): 644-7. Daniel, R Katz, R A Skalka, A M AI40721/AI/NIAID NIH HHS/United States AI40835/AI/NIAID NIH HHS/United States CA71515/CA/NCI NIH HHS/United States etc. Research Support, Non-U.S. Gov't Research Support, U.S. Gov't, P.H.S. United states Science (New York, N.Y.) Science. 1999 Apr 23;284(5414):644-7.

Daniel, R., Marusich, E., Argyris, E., Zhao, R. Y., Skalka, A. M. \& Pomerantz, R. J. (2005). Caffeine inhibits human immunodeficiency virus type 1 transduction of nondividing cells, J Virol 79(4): 2058-65.

Daniel, R., Ramcharan, J., Rogakou, E., Taganov, K. D., Greger, J. G., Bonner, W., Nussenzweig, A., Katz, R. A. \& Skalka, A. M. (2004). Histone H2AX is phosphorylated at sites of retroviral DNA integration but is dispensable for postintegration repair, J Biol Chem 279(44): 45810-4.

D'Ari, R. \& Huisman, O. (1982). DNA replication and indirect induction of the sos response in escherichia coli, Biochimie 64(8-9): 623-7.

Davy, C. \& Doorbar, J. (2007). G2/m cell cycle arrest in the life cycle of viruses, Virology 368(2): 219-26.

De Bont, R. \& van Larebeke, N. (2004). Endogenous DNA damage in humans: a review of quantitative data, Mutagenesis 19(3): 169-85.

de Jager, M., van Noort, J., van Gent, D. C., Dekker, C., Kanaar, R. \& Wyman, C. (2001). Human $\mathrm{rad} 50 / \mathrm{mre} 11$ is a flexible complex that can tether DNA ends, Mol Cell 8(5): 1129-35. 
Delale, T., Paquin, A., Asselin-Paturel, C., Dalod, M., Brizard, G., Bates, E. E., Kastner, P., Chan, S., Akira, S., Vicari, A., Biron, C. A., Trinchieri, G. \& Briere, F. (2005). Myd88-dependent and -independent murine cytomegalovirus sensing for ifn-alpha release and initiation of immune responses in vivo, J Immunol 175(10): 6723-32.

Doil, C., Mailand, N., Bekker-Jensen, S., Menard, P., Larsen, D. H., Pepperkok, R., Ellenberg, J., Panier, S., Durocher, D., Bartek, J., Lukas, J. \& Lukas, C. (2009). Rnf168 binds and amplifies ubiquitin conjugates on damaged chromosomes to allow accumulation of repair proteins, Cell 136(3): 435-46.

Dragoi, A. M., Fu, X., Ivanov, S., Zhang, P., Sheng, L., Wu, D., Li, G. C. \& Chu, W. M. (2005). DNA-pkcs, but not tlr9, is required for activation of akt by cpg-DNA, EMBO J 24(4): 779-89.

D'Silva, I., Pelletier, J. D., Lagueux, J., D'Amours, D., Chaudhry, M. A., Weinfeld, M., Lees-Miller, S. P. \& Poirier, G. G. (1999). Relative affinities of poly(adp-ribose) polymerase and DNA-dependent protein kinase for DNA strand interruptions, Biochim Biophys Acta 1430(1): 119-26.

Duncan, T., Trewick, S. C., Koivisto, P., Bates, P. A., Lindahl, T. \& Sedgwick, B. (2002). Reversal of DNA alkylation damage by two human dioxygenases, Proc Natl Acad Sci U S A 99(26): 16660-5.

Durocher, D. \& Jackson, S. P. (2001). DNA-PK, ATM and ATR as sensors of DNA damage: variations on a theme?, Curr Opin Cell Biol 13(2): 225-31.

Essers, J., Houtsmuller, A. B., van Veelen, L., Paulusma, C., Nigg, A. L., Pastink, A., Vermeulen, W., Hoeijmakers, J. H. \& Kanaar, R. (2002). Nuclear dynamics of rad52 group homologous recombination proteins in response to DNA damage, EMBO J 21(8): 2030-7.

Fernandes-Alnemri, T., Yu, J. W., Datta, P., Wu, J. \& Alnemri, E. S. (2009). Aim2 activates the inflammasome and cell death in response to cytoplasmic DNA, Nature 458(7237): 509-13.

Fernandez-Capetillo, O., Celeste, A. \& Nussenzweig, A. (2003). Focusing on foci: H2AX and the recruitment of DNA-damage response factors, Cell Cycle 2(5): 426-7.

Ferrara, L. \& Kmiec, E. B. (2006). Targeted gene repair activates chk1 and chk2 and stalls replication in corrected cells, DNA Repair (Amst) 5(4): 422-31.

Fortini, P. \& Dogliotti, E. (2007). Base damage and single-strand break repair: mechanisms and functional significance of short- and long-patch repair subpathways, DNA Repair (Amst) 6(4): 398-409.

Fragkos, M., Breuleux, M., Clement, N. \& Beard, P. (2008). Recombinant adeno-associated viral vectors are deficient in provoking a DNA damage response, J Virol 82(15): 7379-87.

Friedberg, E. C. (1995). DNA repair and mutagenesis, American Society for Microbiology, Washington, DC.

Friedberg, E. C. (2001). How nucleotide excision repair protects against cancer, Nat Rev Cancer 1(1): 22-33.

Fugmann, S. D., Lee, A. I., Shockett, P. E., Villey, I. J. \& Schatz, D. G. (2000). The rag proteins and $\mathrm{v}(\mathrm{d}) \mathrm{j}$ recombination: complexes, ends, and transposition, Annu Rev Immunol 18: 495-527.

Geoffroy, M. C. \& Salvetti, A. (2005). Helper functions required for wild type and recombinant adeno-associated virus growth, Curr Gene Ther 5(3): 265-71. 
George, J., Devoret, R. \& Radman, M. (1974). Indirect ultraviolet-reactivation of phage lambda, Proc Natl Acad Sci U S A 71(1): 144-7.

Gerson, S. L. (2004). Mgmt: its role in cancer aetiology and cancer therapeutics, Nat Rev Cancer 4(4): 296-307.

Goodarzi, A. A., Jeggo, P. \& Lobrich, M. (2010). The influence of heterochromatin on DNA double strand break repair: Getting the strong, silent type to relax, DNA Repair (Amst) 9(12): 1273-82.

Goodarzi, A. A., Jonnalagadda, J. C., Douglas, P., Young, D., Ye, R., Moorhead, G. B., Lees-Miller, S. P. \& Khanna, K. K. (2004). Autophosphorylation of ataxia-telangiectasia mutated is regulated by protein phosphatase 2a, EMBO J 23(22): 4451-61.

Grundhoff, A. \& Ganem, D. (2004). Inefficient establishment of kshv latency suggests an additional role for continued lytic replication in kaposi sarcoma pathogenesis, J Clin Invest 113(1): 124-36.

Guainazzi, A. \& Scharer, O. D. (2010). Using synthetic DNA interstrand crosslinks to elucidate repair pathways and identify new therapeutic targets for cancer chemotherapy, Cell Mol Life Sci 67(21): 3683-97.

Guo, Z., Kozlov, S., Lavin, M. F., Person, M. D. \& Paull, T. T. (2010). ATM activation by oxidative stress, Science 330(6003): 517-21.

Hanawalt, P. C. (2002). Subpathways of nucleotide excision repair and their regulation, Oncogene 21(58): 8949-56.

Hartlerode, A. J. \& Scully, R. (2009). Mechanisms of double-strand break repair in somatic mammalian cells, Biochem J 423(2): 157-68.

Helleday, T., Lo, J., van Gent, D. C. \& Engelward, B. P. (2007). DNA double-strand break repair: from mechanistic understanding to cancer treatment, DNA Repair (Amst) 6(7): 923-35.

Helleday, T., Petermann, E., Lundin, C., Hodgson, B. \& Sharma, R. A. (2008). DNA repair pathways as targets for cancer therapy, Nat Rev Cancer 8(3): 193-204.

Hemmi, H., Takeuchi, O., Kawai, T., Kaisho, T., Sato, S., Sanjo, H., Matsumoto, M., Hoshino, K., Wagner, H., Takeda, K. \& Akira, S. (2000). A toll-like receptor recognizes bacterial DNA, Nature 408(6813): 740-5.

Hornung, V., Ablasser, A., Charrel-Dennis, M., Bauernfeind, F., Horvath, G., Caffrey, D. R., Latz, E. \& Fitzgerald, K. A. (2009). Aim2 recognizes cytosolic dsdna and forms a caspase-1-activating inflammasome with asc, Nature 458(7237): 514-8. Hornung, Veit Ablasser, Andrea Charrel-Dennis, Marie Bauernfeind, Franz Horvath, Gabor Caffrey, Daniel R Latz, Eicke Fitzgerald, Katherine A AI-065483/AI/NIAID NIH HHS/United States AI-067497/AI/NIAID NIH HHS/United States R01 AI067497-03/AI/NIAID NIH HHS/United States R01 AI067497-04/AI/NIAID NIH HHS/United States Research Support, N.I.H., Extramural Research Support, Non-U.S. Gov't England Nature Nature. 2009 Mar 26;458(7237):514-8. Epub 2009 Jan 21.

Hsiang, Y. H., Lihou, M. G. \& Liu, L. F. (1989). Arrest of replication forks by drug-stabilized topoisomerase i-DNA cleavable complexes as a mechanism of cell killing by camptothecin, Cancer Res 49(18): 5077-82.

Huang, L. C., Clarkin, K. C. \& Wahl, G. M. (1996). Sensitivity and selectivity of the DNA damage sensor responsible for activating p53-dependent g1 arrest, Proc Natl Acad Sci U S A 93(10): 4827-32. 
Huen, M. S., Grant, R., Manke, I., Minn, K., Yu, X., Yaffe, M. B. \& Chen, J. (2007). Rnf8 transduces the DNA-damage signal via histone ubiquitylation and checkpoint protein assembly, Cell 131(5): 901-14.

Ichijima, Y., Sakasai, R., Okita, N., Asahina, K., Mizutani, S. \& Teraoka, H. (2005). Phosphorylation of histone $\mathrm{H} 2 \mathrm{AX}$ at $\mathrm{m}$ phase in human cells without DNA damage response, Biochem Biophys Res Commun 336(3): 807-12.

Igoucheva, O., Alexeev, V. \& Yoon, K. (2004). Oligonucleotide-directed mutagenesis and targeted gene correction: a mechanistic point of view, Curr Mol Med 4(5): 445-63.

Ikegami, S., Taguchi, T., Ohashi, M., Oguro, M., Nagano, H. \& Mano, Y. (1978). Aphidicolin prevents mitotic cell division by interfering with the activity of DNA polymerase-alpha, Nature 275(5679): 458-60.

Iliakis, G. (2009). Backup pathways of nhej in cells of higher eukaryotes: cell cycle dependence, Radiother Oncol 92(3): 310-5.

Inagaki, A., Schoenmakers, S. \& Baarends, W. M. (2010). DNA double strand break repair, chromosome synapsis and transcriptional silencing in meiosis, Epigenetics 5(4).

Inagaki, K., Ma, C., Storm, T. A., Kay, M. A. \& Nakai, H. (2007). The role of DNA-pkcs and artemis in opening viral DNA hairpin termini in various tissues in mice, J Virol 81(20): 11304-21.

Jang, E. R., Choi, J. D., Park, M. A., Jeong, G., Cho, H. \& Lee, J. S. (2010). ATM modulates transcription in response to histone deacetylase inhibition as part of its DNA damage response, Exp Mol Med 42(3): 195-204.

Jazayeri, A., Balestrini, A., Garner, E., Haber, J. E. \& Costanzo, V. (2008). Mre11-rad50-nbs1-dependent processing of DNA breaks generates oligonucleotides that stimulate ATM activity, Embo J 27(14): 1953-62.

Jeggo, P. A., Taccioli, G. E. \& Jackson, S. P. (1995). Menage a trois: double strand break repair, v(d)j recombination and DNA-PK, Bioessays 17(11): 949-57. Bioessays. 1995 Nov;17(11):949-57.

Jeggo, P. \& Lavin, M. F. (2009). Cellular radiosensitivity: how much better do we understand it?, Int J Radiat Biol 85(12): 1061-81.

Johnson, R. D. \& Jasin, M. (2000). Sister chromatid gene conversion is a prominent double-strand break repair pathway in mammalian cells, EMBO J 19(13): 3398-407.

Jungmichel, S. \& Stucki, M. (2010). Mdc1: The art of keeping things in focus, Chromosoma .

Jurvansuu, J., Raj, K., Stasiak, A. \& Beard, P. (2005). Viral transport of DNA damage that mimics a stalled replication fork, J Virol 79(1): 569-80.

Karpova, A. Y., Trost, M., Murray, J. M., Cantley, L. C. \& Howley, P. M. (2002). Interferon regulatory factor-3 is an in vivo target of DNA-PK, Proc Natl Acad Sci U $S A$ 99(5): 2818-23.

Kastan, M. B. \& Bartek, J. (2004). Cell-cycle checkpoints and cancer, Nature 432(7015): 316-23.

Kilzer, J. M., Stracker, T., Beitzel, B., Meek, K., Weitzman, M. \& Bushman, F. D. (2003). Roles of host cell factors in circularization of retroviral DNA, Virology 314(1): 460-7.

Kim, W. J., Rajasekaran, B. \& Brown, K. D. (2007). Mlh1- and ATM-dependent mapk signaling is activated through $\mathrm{c}-\mathrm{abl}$ in response to the alkylator n-methyl-n'-nitro-n'-nitrosoguanidine, J Biol Chem 282(44): 32021-31.

Kim, Y. C., Gerlitz, G., Furusawa, T., Catez, F., Nussenzweig, A., Oh, K. S., Kraemer, K. H., Shiloh, Y. \& Bustin, M. (2009). Activation of ATM depends on chromatin interactions occurring before induction of DNA damage, Nat Cell Biol 11(1): 92-6. 
Knipscheer, P., Raschle, M., Smogorzewska, A., Enoiu, M., Ho, T. V., Scharer, O. D., Elledge, S. J. \& Walter, J. C. (2009). The fanconi anemia pathway promotes replication-dependent DNA interstrand cross-link repair, Science 326(5960): 1698-701.

Koch, C. A., Agyei, R., Galicia, S., Metalnikov, P., O’Donnell, P., Starostine, A., Weinfeld, M. \& Durocher, D. (2004). XRCC4 physically links DNA end processing by polynucleotide kinase to DNA ligation by DNA ligase iv, EMBO J 23(19): 3874-85.

Kohn, K. W. (1999). Molecular interaction map of the mammalian cell cycle control and DNA repair systems, Mol Biol Cell 10(8): 2703-34.

Kohn, K. W., Pommier, Y., Kerrigan, D., Markovits, J. \& Covey, J. M. (1987). Topoisomerase ii as a target of anticancer drug action in mammalian cells, NCI Monogr (4): 61-71.

Kolas, N. K., Chapman, J. R., Nakada, S., Ylanko, J., Chahwan, R., Sweeney, F. D., Panier, S., Mendez, M., Wildenhain, J., Thomson, T. M., Pelletier, L., Jackson, S. P. \& Durocher, D. (2007). Orchestration of the DNA-damage response by the rnf8 ubiquitin ligase, Science 318(5856): 1637-40.

Kudoh, A., Fujita, M., Zhang, L., Shirata, N., Daikoku, T., Sugaya, Y., Isomura, H., Nishiyama, Y. \& Tsurumi, T. (2005). Epstein-barr virus lytic replication elicits ATM checkpoint signal transduction while providing an s-phase-like cellular environment, J Biol Chem 280(9): 8156-63.

Kumagai, A., Lee, J., Yoo, H. Y. \& Dunphy, W. G. (2006). Topbp1 activates the ATR-atrip complex, Cell 124(5): 943-55.

Kunkel, T. A. \& Erie, D. A. (2005). DNA mismatch repair, Annu Rev Biochem 74: 681-710.

Lau, A., Swinbank, K. M., Ahmed, P. S., Taylor, D. L., Jackson, S. P., Smith, G. C. \& O'Connor, M. J. (2005). Suppression of hiv-1 infection by a small molecule inhibitor of the ATM kinase, Nat Cell Biol 7(5): 493-500.

Lee, J. H. \& Paull, T. T. (2004). Direct activation of the ATM protein kinase by the mre11/rad50/nbs1 complex, Science 304(5667): 93-6.

Lee, J. H. \& Paull, T. T. (2005). ATM activation by DNA double-strand breaks through the mre11-rad50-nbs1 complex, Science 308(5721): 551-4.

Lee-Kirsch, M. A., Gong, M., Chowdhury, D., Senenko, L., Engel, K., Lee, Y. A., de Silva, U., Bailey, S. L., Witte, T., Vyse, T. J., Kere, J., Pfeiffer, C., Harvey, S., Wong, A., Koskenmies, S., Hummel, O., Rohde, K., Schmidt, R. E., Dominiczak, A. F., Gahr, M., Hollis, T., Perrino, F. W., Lieberman, J. \& Hubner, N. (2007). Mutations in the gene encoding the $3^{\prime}-5^{\prime}$ DNA exonuclease trex1 are associated with systemic lupus erythematosus, Nat Genet 39(9): 1065-7.

Li, G. M. (1999). The role of mismatch repair in DNA damage-induced apoptosis, Oncol Res 11(9): 393-400.

Li, G. M. (2008). Mechanisms and functions of DNA mismatch repair, Cell Res 18(1): 85-98.

Li, J. J. \& Deshaies, R. J. (1993). Exercising self-restraint: discouraging illicit acts of $s$ and $m$ in eukaryotes, Cell 74(2): 223-6.

Li, L., Olvera, J. M., Yoder, K. E., Mitchell, R. S., Butler, S. L., Lieber, M., Martin, S. L. \& Bushman, F. D. (2001). Role of the non-homologous DNA end joining pathway in the early steps of retroviral infection, EMBO J 20(12): 3272-81.

Li, L. \& Zou, L. (2005). Sensing, signaling, and responding to DNA damage: organization of the checkpoint pathways in mammalian cells, J Cell Biochem 94(2): 298-306. 
Lilley, C. E., Carson, C. T., Muotri, A. R., Gage, F. H. \& Weitzman, M. D. (2005). DNA repair proteins affect the lifecycle of herpes simplex virus 1, Proc Natl Acad Sci $U$ $S$ A 102(16): 5844-9.

Lilley, C. E., Schwartz, R. A. \& Weitzman, M. D. (2007). Using or abusing: viruses and the cellular DNA damage response, Trends Microbiol 15(3): 119-26.

Liu, Y. \& Maizels, N. (2000). Coordinated response of mammalian rad51 and rad52 to DNA damage, EMBO Rep 1(1): 85-90.

Liu, Y. \& West, S. C. (2004). Happy hollidays: 40th anniversary of the holliday junction, Nat Rev Mol Cell Biol 5(11): 937-44.

Lobrich, M. \& Jeggo, P. A. (2007). The impact of a negligent g2/m checkpoint on genomic instability and cancer induction, Nat Rev Cancer 7(11): 861-9.

Lopez-Contreras, A. J. \& Fernandez-Capetillo, O. (2010). The ATR barrier to replication-born DNA damage, DNA Repair (Amst) 9(12): 1249-55.

Lukas, C., Falck, J., Bartkova, J., Bartek, J. \& Lukas, J. (2003). Distinct spatiotemporal dynamics of mammalian checkpoint regulators induced by DNA damage, Nat Cell Biol 5(3): 255-60.

Lukas, J., Lukas, C. \& Bartek, J. (2004). Mammalian cell cycle checkpoints: signalling pathways and their organization in space and time, DNA Repair (Amst) 3(8-9): 997-1007.

Lund, J., Sato, A., Akira, S., Medzhitov, R. \& Iwasaki, A. (2003). Toll-like receptor 9-mediated recognition of herpes simplex virus-2 by plasmacytoid dendritic cells, J Exp Med 198(3): 513-20.

Lundin, C., Erixon, K., Arnaudeau, C., Schultz, N., Jenssen, D., Meuth, M. \& Helleday, T. (2002). Different roles for nonhomologous end joining and homologous recombination following replication arrest in mammalian cells, Mol Cell Biol 22(16): 5869-78.

Luo, M. H., Rosenke, K., Czornak, K. \& Fortunato, E. A. (2007). Human cytomegalovirus disrupts both ataxia telangiectasia mutated protein (ATM)- and ATM-rad3-related kinase-mediated DNA damage responses during lytic infection, J Virol 81(4): 1934-50.

Luo, Y., Chen, A. Y. \& Qiu, J. (2011). Bocavirus infection induces a DNA damage response that facilitates viral DNA replication and mediates cell death, J Virol 85(1): 133-45.

Ma, Y., Pannicke, U., Schwarz, K. \& Lieber, M. R. (2002). Hairpin opening and overhang processing by an artemis/DNA-dependent protein kinase complex in nonhomologous end joining and $\mathrm{v}(\mathrm{d}) \mathrm{j}$ recombination, Cell 108(6): 781-94.

Malanga, M. \& Althaus, F. R. (2005). The role of poly(adp-ribose) in the DNA damage signaling network, Biochem Cell Biol 83(3): 354-64.

Malanga, M., Pleschke, J. M., Kleczkowska, H. E. \& Althaus, F. R. (1998). Poly(adp-ribose) binds to specific domains of p53 and alters its DNA binding functions, J Biol Chem 273(19): 11839-43.

Masson, C., Bury-Mone, S., Guiot, E., Saez-Cirion, A., Schoevaert-Brossault, D., Brachet-Ducos, C., Delelis, O., Subra, F., Jeanson-Leh, L. \& Mouscadet, J. F. (2007). Ku80 participates in the targeting of retroviral transgenes to the chromatin of cho cells, J Virol 81(15): 7924-32.

Matsuoka, S., Ballif, B. A., Smogorzewska, A., McDonald, E. R., r., Hurov, K. E., Luo, J., Bakalarski, C. E., Zhao, Z., Solimini, N., Lerenthal, Y., Shiloh, Y., Gygi, S. P. \& Elledge, S. J. (2007). ATM and ATR substrate analysis reveals extensive protein networks responsive to DNA damage, Science 316(5828): 1160-6. 
Mazumdar, M., Lee, J. H., Sengupta, K., Ried, T., Rane, S. \& Misteli, T. (2006). Tumor formation via loss of a molecular motor protein, Curr Biol 16(15): 1559-64.

McAdams, H. H. \& Arkin, A. (1999). It's a noisy business! genetic regulation at the nanomolar scale, Trends Genet 15(2): 65-9.

Misteli, T. \& Soutoglou, E. (2009). The emerging role of nuclear architecture in DNA repair and genome maintenance, Nat Rev Mol Cell Biol 10(4): 243-54.

Moreno-Herrero, F., de Jager, M., Dekker, N. H., Kanaar, R., Wyman, C. \& Dekker, C. (2005). Mesoscale conformational changes in the DNA-repair complex rad50/mre11/nbs 1 upon binding DNA, Nature 437(7057): 440-3.

Mosesso, P., Palitti, F., Pepe, G., Pinero, J., Bellacima, R., Ahnstrom, G. \& Natarajan, A. T. (2010). Relationship between chromatin structure, DNA damage and repair following x-irradiation of human lymphocytes, Mutat Res 701(1): 86-91.

Moshous, D., Callebaut, I., de Chasseval, R., Corneo, B., Cavazzana-Calvo, M., Le Deist, F., Tezcan, I., Sanal, O., Bertrand, Y., Philippe, N., Fischer, A. \& de Villartay, J. P. (2001). Artemis, a novel DNA double-strand break repair/v(d)j recombination protein, is mutated in human severe combined immune deficiency, Cell 105(2): 177-86.

Nash, K., Chen, W., Salganik, M. \& Muzyczka, N. (2009). Identification of cellular proteins that interact with the adeno-associated virus rep protein, J Virol 83(1): 454-69.

Nichols, G. J., Schaack, J. \& Ornelles, D. A. (2009). Widespread phosphorylation of histone $\mathrm{H} 2 \mathrm{AX}$ by species $\mathrm{c}$ adenovirus infection requires viral DNA replication, J Virol 83(12): 5987-98.

Nick McElhinny, S. A., Havener, J. M., Garcia-Diaz, M., Juarez, R., Bebenek, K., Kee, B. L., Blanco, L., Kunkel, T. A. \& Ramsden, D. A. (2005). A gradient of template dependence defines distinct biological roles for family $\mathrm{x}$ polymerases in nonhomologous end joining, Mol Cell 19(3): 357-66.

Nur, E. K. A., Li, T. K., Zhang, A., Qi, H., Hars, E. S. \& Liu, L. F. (2003). Single-stranded DNA induces ataxia telangiectasia mutant (ATM)/p53-dependent DNA damage and apoptotic signals, J Biol Chem 278(14): 12475-81.

Orelli, B., McClendon, T. B., Tsodikov, O. V., Ellenberger, T., Niedernhofer, L. J. \& Scharer, O. D. (2010). The xpa-binding domain of ercc1 is required for nucleotide excision repair but not other DNA repair pathways, J Biol Chem 285(6): 3705-12.

Park, Y., Lee, S. W. \& Sung, Y. C. (2002). Cutting edge: Cpg DNA inhibits dendritic cell apoptosis by up-regulating cellular inhibitor of apoptosis proteins through the phosphatidylinositide-3'-oh kinase pathway, J Immunol 168(1): 5-8.

Patil, S. D., Rhodes, D. G. \& Burgess, D. J. (2005). DNA-based therapeutics and DNA delivery systems: a comprehensive review, Aaps J 7(1): E61-77.

Paull, T. T. \& Gellert, M. (1998). The 3' to 5' exonuclease activity of mre 11 facilitates repair of DNA double-strand breaks, Mol Cell 1(7): 969-79.

Paull, T. T. \& Gellert, M. (1999). Nbs1 potentiates atp-driven DNA unwinding and endonuclease cleavage by the mre11/rad50 complex, Genes Dev 13(10): 1276-88.

Pellegrini, L., Yu, D. S., Lo, T., Anand, S., Lee, M., Blundell, T. L. \& Venkitaraman, A. R. (2002). Insights into DNA recombination from the structure of a rad51-BRCA2 complex, Nature 420(6913): 287-93.

Peng, Y., Woods, R. G., Beamish, H., Ye, R., Lees-Miller, S. P., Lavin, M. F. \& Bedford, J. S. (2005). Deficiency in the catalytic subunit of DNA-dependent protein kinase causes down-regulation of ATM, Cancer Res 65(5): 1670-7. 
Perry, J. J., Yannone, S. M., Holden, L. G., Hitomi, C., Asaithamby, A., Han, S., Cooper, P. K., Chen, D. J. \& Tainer, J. A. (2006). Wrn exonuclease structure and molecular mechanism imply an editing role in DNA end processing, Nat Struct Mol Biol 13(5): 414-22.

Polo, S. E. \& Jackson, S. P. (2011). Dynamics of DNA damage response proteins at DNA breaks: a focus on protein modifications, Genes Dev 25(5): 409-33.

Quanz, M., Berthault, N., Roulin, C., Roy, M., Herbette, A., Agrario, C., Alberti, C., Josserand, V., Coll, J. L., Sastre-Garau, X., Cosset, J. M., Larue, L., Sun, J. S. \& Dutreix, M. (2009). Small-molecule drugs mimicking DNA damage: a new strategy for sensitizing tumors to radiotherapy, Clin Cancer Res 15(4): 1308-16.

Quanz, M., Chassoux, D., Berthault, N., Agrario, C., Sun, J. S. \& Dutreix, M. (2009). Hyperactivation of DNA-PK by double-strand break mimicking molecules disorganizes DNA damage response, PLoS One 4(7): e6298.

Raderschall, E., Golub, E. I. \& Haaf, T. (1999). Nuclear foci of mammalian recombination proteins are located at single-stranded DNA regions formed after DNA damage, Proc Natl Acad Sci U S A 96(5): 1921-6.

Radford, I. R. (1985). The level of induced DNA double-strand breakage correlates with cell killing after x-irradiation, Int J Radiat Biol Relat Stud Phys Chem Med 48(1): 45-54.

Raschle, M., Knipscheer, P., Enoiu, M., Angelov, T., Sun, J., Griffith, J. D., Ellenberger, T. E., Scharer, O. D. \& Walter, J. C. (2008). Mechanism of replication-coupled DNA interstrand crosslink repair, Cell 134(6): 969-80.

Rathinam, V. A. \& Fitzgerald, K. A. (2011). Innate immune sensing of DNA viruses, Virology 411(2): 153-62.

Reardon, J. T. \& Sancar, A. (2005). Nucleotide excision repair, Prog Nucleic Acid Res Mol Biol 79: 183-235.

Riballo, E., Kuhne, M., Rief, N., Doherty, A., Smith, G. C., Recio, M. J., Reis, C., Dahm, K., Fricke, A., Krempler, A., Parker, A. R., Jackson, S. P., Gennery, A., Jeggo, P. A. \& Lobrich, M. (2004). A pathway of double-strand break rejoining dependent upon ATM, artemis, and proteins locating to gamma-H2AX foci, Mol Cell 16(5): 715-24.

Rosidi, B., Wang, M., Wu, W., Sharma, A., Wang, H. \& Iliakis, G. (2008). Histone h1 functions as a stimulatory factor in backup pathways of nhej, Nucleic Acids Res 36(5): 1610-23.

Rossi, J. J. (2004). Medicine: a cholesterol connection in rnai, Nature 432(7014): 155-6.

Rouleau, M., Patel, A., Hendzel, M. J., Kaufmann, S. H. \& Poirier, G. G. (2010). Parp inhibition: Parp1 and beyond, Nat Rev Cancer 10(4): 293-301.

Rupnik, A., Grenon, M. \& Lowndes, N. (2008). The mrn complex, Curr Biol 18(11): R455-7.

Sakurai, Y., Komatsu, K., Agematsu, K. \& Matsuoka, M. (2009). DNA double strand break repair enzymes function at multiple steps in retroviral infection, Retrovirology 6: 114.

Sartori, A. A., Lukas, C., Coates, J., Mistrik, M., Fu, S., Bartek, J., Baer, R., Lukas, J. \& Jackson, S. P. (2007). Human ctip promotes DNA end resection, Nature 450(7169): 509-14.

Schiavone, N., Papucci, L., Luciani, P., Lapucci, A., Donnini, M. \& Capaccioli, S. (2000). Induction of apoptosis and mitosis inhibition by degraded DNA lipotransfection mimicking genotoxic drug effects, Biochem Biophys Res Commun 270(2): 406-14.

Schlacher, K. \& Goodman, M. F. (2007). Lessons from 50 years of sos DNA-damage-induced mutagenesis, Nat Rev Mol Cell Biol 8(7): 587-94. 
Schwartz, R. A., Carson, C. T., Schuberth, C. \& Weitzman, M. D. (2009). Adeno-associated virus replication induces a DNA damage response coordinated by DNA-dependent protein kinase, J Virol 83(12): 6269-78.

Scully, R., Chen, J., Ochs, R. L., Keegan, K., Hoekstra, M., Feunteun, J. \& Livingston, D. M. (1997). Dynamic changes of BRCA1 subnuclear location and phosphorylation state are initiated by DNA damage, Cell 90(3): 425-35.

Sester, D. P., Brion, K., Trieu, A., Goodridge, H. S., Roberts, T. L., Dunn, J., Hume, D. A., Stacey, K. J. \& Sweet, M. J. (2006). Cpg DNA activates survival in murine macrophages through tlr9 and the phosphatidylinositol 3-kinase-akt pathway, $J$ Immunol 177(7): 4473-80.

Shell, S. M., Li, Z., Shkriabai, N., Kvaratskhelia, M., Brosey, C., Serrano, M. A., Chazin, W. J., Musich, P. R. \& Zou, Y. (2009). Checkpoint kinase ATR promotes nucleotide excision repair of uv-induced DNA damage via physical interaction with xeroderma pigmentosum group a, J Biol Chem 284(36): 24213-22.

Shimodaira, H., Yoshioka-Yamashita, A., Kolodner, R. D. \& Wang, J. Y. (2003). Interaction of mismatch repair protein pms2 and the p53-related transcription factor p73 in apoptosis response to cisplatin, Proc Natl Acad Sci U S A 100(5): 2420-5.

Shreeram, S., Hee, W. K., Demidov, O. N., Kek, C., Yamaguchi, H., Fornace, A. J., J., Anderson, C. W., Appella, E. \& Bulavin, D. V. (2006). Regulation of ATM/p53-dependent suppression of myc-induced lymphomas by wip1 phosphatase, J Exp Med 203(13): 2793-9.

Skalka, A. M. \& Katz, R. A. (2005). Retroviral DNA integration and the DNA damage response, Cell Death Differ 12 Suppl 1: 971-8.

Smith, J., Tho, L. M., Xu, N. \& Gillespie, D. A. (2010). The ATM-chk2 and ATR-chk1 pathways in DNA damage signaling and cancer, Adv Cancer Res 108: 73-112.

Soutoglou, E. \& Misteli, T. (2008). Activation of the cellular DNA damage response in the absence of DNA lesions, Science 320(5882): 1507-10.

Stewart, G. S., Panier, S., Townsend, K., Al-Hakim, A. K., Kolas, N. K., Miller, E. S., Nakada, S., Ylanko, J., Olivarius, S., Mendez, M., Oldreive, C., Wildenhain, J., Tagliaferro, A., Pelletier, L., Taubenheim, N., Durandy, A., Byrd, P. J., Stankovic, T., Taylor, A. M. \& Durocher, D. (2009). The riddle syndrome protein mediates a ubiquitin-dependent signaling cascade at sites of DNA damage, Cell 136(3): 420-34.

Stiff, T., O’Driscoll, M., Rief, N., Iwabuchi, K., Lobrich, M. \& Jeggo, P. A. (2004). ATM and DNA-PK function redundantly to phosphorylate H2AX after exposure to ionizing radiation, Cancer Res 64(7): 2390-6.

Stracker, T. H., Carson, C. T. \& Weitzman, M. D. (2002). Adenovirus oncoproteins inactivate the mre11-rad50-nbs1 DNA repair complex, Nature 418(6895): 348-52.

Stracker, T. H., Cassell, G. D., Ward, P., Loo, Y. M., van Breukelen, B., Carrington-Lawrence, S. D., Hamatake, R. K., van der Vliet, P. C., Weller, S. K., Melendy, T. \& Weitzman, M. D. (2004). The rep protein of adeno-associated virus type 2 interacts with single-stranded DNA-binding proteins that enhance viral replication, J Virol 78(1): 441-53.

Strumberg, D., Pilon, A. A., Smith, M., Hickey, R., Malkas, L. \& Pommier, Y. (2000). Conversion of topoisomerase i cleavage complexes on the leading strand of ribosomal DNA into 5'-phosphorylated DNA double-strand breaks by replication runoff, Mol Cell Biol 20(11): 3977-87. 
Sy, S. M., Huen, M. S. \& Chen, J. (2009). Palb2 is an integral component of the BRCA complex required for homologous recombination repair, Proc Natl Acad Sci U S A 106(17): 7155-60.

Takaoka, A. \& Taniguchi, T. (2008). Cytosolic DNA recognition for triggering innate immune responses, Adv Drug Deliv Rev 60(7): 847-57.

Takaoka, A., Wang, Z., Choi, M. K., Yanai, H., Negishi, H., Ban, T., Lu, Y., Miyagishi, M., Kodama, T., Honda, K., Ohba, Y. \& Taniguchi, T. (2007). Dai (dlm-1/zbp1) is a cytosolic DNA sensor and an activator of innate immune response, Nature 448(7152): 501-5.

Toledo, L. I., Murga, M., Gutierrez-Martinez, P., Soria, R. \& Fernandez-Capetillo, O. (2008). ATR signaling can drive cells into senescence in the absence of DNA breaks, Genes Dev 22(3): 297-302.

Van Dyck, E., Stasiak, A. Z., Stasiak, A. \& West, S. C. (2001). Visualization of recombination intermediates produced by rad52-mediated single-strand annealing, EMBO Rep 2(10): 905-9.

van Heemst, D., Brugmans, L., Verkaik, N. S. \& van Gent, D. C. (2004). End-joining of blunt DNA double-strand breaks in mammalian fibroblasts is precise and requires DNA-PK and XRCC4, DNA Repair (Amst) 3(1): 43-50.

Vilaysane, A. \& Muruve, D. A. (2009). The innate immune response to DNA, Semin Immunol 21(4): 208-14.

Wagner, H. (2004). The immunobiology of the tlr9 subfamily, Trends Immunol 25(7): 381-6.

Wang, S., Guo, M., Ouyang, H., Li, X., Cordon-Cardo, C., Kurimasa, A., Chen, D. J., Fuks, Z., Ling, C. C. \& Li, G. C. (2000). The catalytic subunit of DNA-dependent protein kinase selectively regulates p53-dependent apoptosis but not cell-cycle arrest, Proc Natl Acad Sci U S A 97(4): 1584-8.

Wang, X., Ohnishi, K., Takahashi, A. \& Ohnishi, T. (1998). Poly(adp-ribosyl)ation is required for p53-dependent signal transduction induced by radiation, Oncogene 17(22): 2819-25.

Wang, X., Peterson, C. A., Zheng, H., Nairn, R. S., Legerski, R. J. \& Li, L. (2001). Involvement of nucleotide excision repair in a recombination-independent and error-prone pathway of DNA interstrand cross-link repair, Mol Cell Biol 21(3): 713-20.

Wang, Y., Li, H., Tang, Q., Maul, G. G. \& Yuan, Y. (2008). Kaposi's sarcoma-associated herpesvirus ori-lyt-dependent DNA replication: involvement of host cellular factors, J Virol 82(6): 2867-82.

Ward, I. \& Chen, J. (2004). Early events in the DNA damage response, Curr Top Dev Biol 63: 1-35.

Ward, I. M. \& Chen, J. (2001). Histone H2AX is phosphorylated in an ATR-dependent manner in response to replicational stress, J Biol Chem 276(51): 47759-62.

Ward, J. F. (1975). Radiation-induced strand breakage in DNA, Basic Life Sci 5B: 471-2.

Weitzman, M. D., Carson, C. T., Schwartz, R. A. \& Lilley, C. E. (2004). Interactions of viruses with the cellular DNA repair machinery, DNA Repair (Amst) 3(8-9): 1165-73.

Weitzman, M. D. \& Ornelles, D. A. (2005). Inactivating intracellular antiviral responses during adenovirus infection, Oncogene 24(52): 7686-96.

Weterings, E. \& Chen, D. J. (2007). DNA-dependent protein kinase in nonhomologous end joining: a lock with multiple keys?, J Cell Biol 179(2): 183-6. 
Weterings, E. \& van Gent, D. C. (2004). The mechanism of non-homologous end-joining: a synopsis of synapsis, DNA Repair (Amst) 3(11): 1425-35.

Wieler, S., Gagne, J. P., Vaziri, H., Poirier, G. G. \& Benchimol, S. (2003). Poly(adp-ribose) polymerase-1 is a positive regulator of the p53-mediated g1 arrest response following ionizing radiation, J Biol Chem 278(21): 18914-21.

Wilkinson, D. E. \& Weller, S. K. (2006). Herpes simplex virus type i disrupts the ATR-dependent DNA-damage response during lytic infection, J Cell Sci 119(Pt 13): 2695-703.

Wyman, C. \& Kanaar, R. (2006). DNA double-strand break repair: all's well that ends well, Annu Rev Genet 40: 363-83.

Yanai, H., Savitsky, D., Tamura, T. \& Taniguchi, T. (2009). Regulation of the cytosolic DNA-sensing system in innate immunity: a current view, Curr Opin Immunol 21(1): 17-22.

Yang, J., Yu, Y., Hamrick, H. E. \& Duerksen-Hughes, P. J. (2003). ATM, ATR and DNA-PK: initiators of the cellular genotoxic stress responses, Carcinogenesis 24(10): 1571-80.

Yang, Y. G., Lindahl, T. \& Barnes, D. E. (2007). Trex1 exonuclease degrades ssdna to prevent chronic checkpoint activation and autoimmune disease, Cell 131(5): 873-86.

Yarosh, D. B. (2001). Why is DNA damage signaling so complicated? chaos and molecular signaling, Environ Mol Mutagen 38(2-3): 132-4.

Yoshioka, K., Yoshioka, Y. \& Hsieh, P. (2006). ATR kinase activation mediated by mutsalpha and mutlalpha in response to cytotoxic o6-methylguanine adducts, Mol Cell 22(4): 501-10.

Yun, M. H. \& Hiom, K. (2009). Ctip-BRCA1 modulates the choice of DNA double-strand-break repair pathway throughout the cell cycle, Nature 459(7245): 460-3.

Zhu, Y., Hu, J., Hu, Y. \& Liu, W. (2009). Targeting DNA repair pathways: a novel approach to reduce cancer therapeutic resistance, Cancer Treat Rev 35(7): 590-6. 


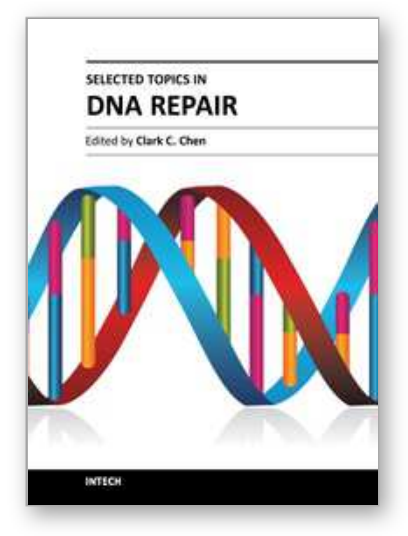

\author{
Selected Topics in DNA Repair \\ Edited by Prof. Clark Chen
}

ISBN 978-953-307-606-5

Hard cover, 572 pages

Publisher InTech

Published online 26, October, 2011

Published in print edition October, 2011

This book is intended for students and scientists working in the field of DNA repair, focusing on a number of topics ranging from DNA damaging agents and mechanistic insights to methods in DNA repair and insights into therapeutic strategies. These topics demonstrate how scientific ideas are developed, tested, dialogued, and matured as it is meant to discuss key concepts in DNA repair. The book should serve as a supplementary text in courses and seminars as well as a general reference for biologists with an interest in DNA repair.

\title{
How to reference
}

In order to correctly reference this scholarly work, feel free to copy and paste the following:

Maria Quanz, Amélie Croset and Marie Dutreix (2011). SiDNA and Other Tools for the Indirect Induction of DNA Damage Responses, Selected Topics in DNA Repair, Prof. Clark Chen (Ed.), ISBN: 978-953-307-606-5, InTech, Available from: http://www.intechopen.com/books/selected-topics-in-dna-repair/sidna-and-other-toolsfor-the-indirect-induction-of-dna-damage-responses

\section{INTECH}

open science | open minds

\author{
InTech Europe \\ University Campus STeP Ri \\ Slavka Krautzeka 83/A \\ 51000 Rijeka, Croatia \\ Phone: +385 (51) 770447 \\ Fax: +385 (51) 686166 \\ www.intechopen.com
}

\author{
InTech China \\ Unit 405, Office Block, Hotel Equatorial Shanghai \\ No.65, Yan An Road (West), Shanghai, 200040, China \\ 中国上海市延安西路65号上海国际贵都大饭店办公楼 405 单元 \\ Phone: +86-21-62489820 \\ Fax: $+86-21-62489821$
}


(C) 2011 The Author(s). Licensee IntechOpen. This is an open access article distributed under the terms of the Creative Commons Attribution 3.0 License, which permits unrestricted use, distribution, and reproduction in any medium, provided the original work is properly cited. 